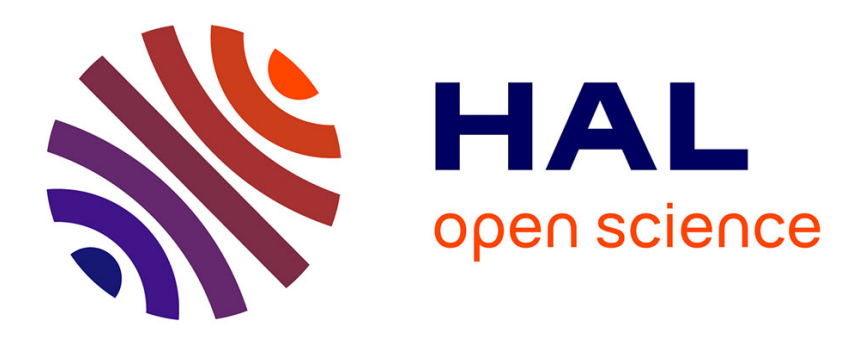

\title{
The contribution of improved joint survival conditions to living standards: An equivalent consumption approach
}

Grégory Ponthière

\section{To cite this version:}

Grégory Ponthière. The contribution of improved joint survival conditions to living standards: An equivalent consumption approach. 2015. halshs-01194427

\section{HAL Id: halshs-01194427 \\ https://shs.hal.science/halshs-01194427}

Preprint submitted on 7 Sep 2015

HAL is a multi-disciplinary open access archive for the deposit and dissemination of scientific research documents, whether they are published or not. The documents may come from teaching and research institutions in France or abroad, or from public or private research centers.
L'archive ouverte pluridisciplinaire HAL, est destinée au dépôt et à la diffusion de documents scientifiques de niveau recherche, publiés ou non, émanant des établissements d'enseignement et de recherche français ou étrangers, des laboratoires publics ou privés. 


\title{
PARISSCHOOL OF ECONOMICS
}

WORKING PAPER Nº $2015-27$

The contribution of improved joint survival conditions to living standards:

An equivalent consumption approach

\author{
Grégory Ponthière
}

JEL Codes: I31, J10

Keywords: Mortality, Joint survival, Coexistence, Measurement, Standards of living

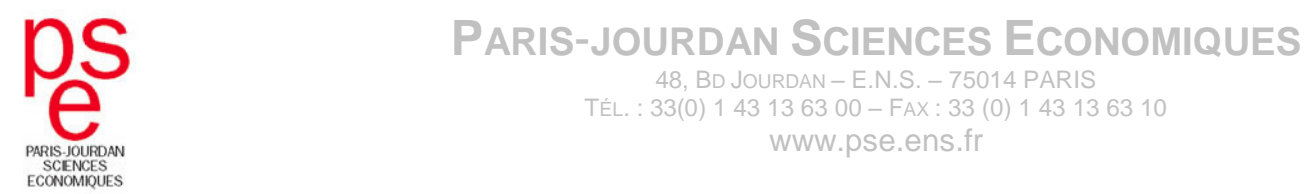




\title{
The contribution of improved joint survival conditions to living standards: An equivalent consumption approach*
}

\author{
Gregory Ponthiere ${ }^{\dagger \ddagger}$
}

August 31, 2015

\begin{abstract}
Individuals care not only about their own survival, but also about the survival of other persons. However, little attention has been paid so far to measuring the contribution of longer coexistence time to living standards. For that purpose, we develop a measure of coexistence time - the joint life expectancy -, which quantifies the average duration of existence for a group of persons. Then, using a lifecycle model with risky lifetime, we construct an equivalent consumption measure incorporating gains in single and joint life expectancies. An empirical application to France (1820-2010) shows that, assuming independent individual mortality risks, the rise in joint life expectancies contributed to improve standards of living significantly. We examine the robustness of that result to the introduction of dependent mortality risks using copulas, and we show that equivalent consumption patterns are robust to introducing risk dependence.

Keywords: mortality, joint survival, coexistence, measurement, standards of living.

JEL codes: I31, J10.
\end{abstract}

\footnotetext{
*The author would like to thank Koen Decancq, Marc Fleurbaey, André Masson, Julien Tomas, Alain Villemeur, Hélène Xuan, Stéphane Zuber, two anonymous referees, as well as participants of seminars at University Paris Dauphine and at the Caisse des Dépôts et Consignations for helpful comments on this paper.

${ }^{\dagger}$ University Paris East (ERUDITE) and Paris School of Economics. Address: Ecole Normale Superieure, 48 boulevard Jourdan, Building A, Office 202, 75014 Paris, France. E-mail: gregory.ponthiere@ens.fr

${ }^{\ddagger}$ Gregory Ponthiere acknowledges the financial support of the ANR Equirisk (Equity in Risky Intertemporal Economic Environments) (ANR-12-INEG-0006-01).
} 


\section{Introduction}

During the last decades, economists have paid a large attention to the measurement of the economic performance of nations through time. Following the pioneer Is growth obsolete? by Nordhaus and Tobin (1972), the concept of "economic performance" under study consists in the capacity of nations to overcome all sources of scarcity (North 1994). Its measurement includes not only the consumption of goods, but also other dimensions of standards of living, such as the enjoyment of leisure time and of a clean environment.

Among the dimensions of well-being under study, longevity has received a significant attention. As underlined by Sen $(1973,1998)$, whatever the goals and life plans one has, some quantity of time is necessary to achieve those goals. This makes longevity achievements a central aspect of economic performance.

In some pioneer writings, Usher $(1973,1980)$ proposed to construct a measure of economic performance taking longevity achievements into account, by computing the equivalent income, that is, a hypothetical income such that, if enjoyed with some survival conditions of reference (usually the ones prevailing at a base year), this income would make a representative individual indifferent between that hypothetical situation and his current standards of living. As such, the equivalent income allows for the incorporation, within monetary measures of standards of living, of variations in the quantity of life.

Usher's works gave rise to numerous applications. Williamson (1984) applied Usher's method to the measurement of standards of living in England and Wales (1781-1931). Crafts (1997) provided, on the basis of equivalent incomes, a quantitative comparison of standards of living across Europe during the 19th and 20th centuries. Costa and Steckel (1997) used equivalent incomes to revisit the measurement of living standards during the early Industrial Revolution in the U.S., a period during which consumption standards improved, whereas survival conditions temporarily worsened. Other recent applications include Sandberg and Steckel (1997) on the Industrial Revolution in Sweden, Nordhaus (2003) on the contribution of health improvements to living standards in the U.S. during the 20th century, and Becker et al (2005) on inequalities in living standards around the world in the 20th century. Murphy and Topel (2006) and Hall and Jones (2007) also used the equivalent income approach to evaluate the benefits from health expenditures. More recently, Fleurbaey and Gaulier (2009) constructed equivalent incomes taking into account not only longevity achievements, but, also, employment, leisure time and inequalities.

Although those studies cast original light on the evolution of standards of living over the last centuries, these considered longevity gains from a particular perspective, that is, from the perspective of individuals concerned only with their own survival. In those studies, the construction of an equivalent income is based on a life cycle model where individuals derive utility only from their own survival, independently from the survival of other persons. Whereas that assumption is analytically convenient, it constitutes a strong simplification of reality. In the real world, individuals care not only about their own survival, but also about the survival of other persons (spouse, children, parents, etc.). 
This concern for joint survival or coexistence is far from marginal. Empirical studies reveal that coexistence matters a lot for life satisfaction. For instance, Blanchflower and Oswald (2004) showed that not less than $\$ 100,000$ per year would be necessary to compensate, in welfare terms, a person having lost his/her spouse. In the light of such a high compensation, one can expect that individuals have strong concerns for joint survival with other persons, and that the value of coexistence time is large. ${ }^{1}$ But existing studies - such as Usher $(1973,1980)$ and the other studies mentioned above - focused on a representative individual only concerned with his own survival, and, therefore, could not take concerns for joint survival into account.

The goal of this paper is to quantify the contribution of improved joint survival conditions to the measurement of living standards. For that purpose, we explore how existing monetary equivalent measures can be extended to incorporate the value of joint survival. Taking coexistence into account raises two main challenges. First, the question of the measurement of coexistence time: how can one measure coexistence? Second, how can one construct a monetary equivalent taking into account the value of improved joint survival?

In order to quantify coexistence time, we develop measures of joint life expectancy. The joint life expectancy is the mathematical expectation of the duration of life for a group of persons (the death of a single member of the group leading to the end of the whole group), conditionally on the survival conditions prevailing at a given period of time. As such, joint life expectancies extend the widely used concept of (single) life expectancy, i.e. the mathematical expectation of the duration of life for a single person, also conditionally on the survival conditions prevailing at a given period of time. Joint life expectancies measure the coexistence phenomenon under the exclusive prism of joint survival, without capturing the impact of other phenomena (such as divorce, separation, spatial mobility, etc.) on the quantity of time actually lived together by some persons.

Regarding the measurement of standards of living, we develop a life cycle model with risky lifetime, and we construct a constant consumption profile equivalent incorporating the monetary value of variations not only in the duration of existence (measured by single life expectancies), but also in the duration of coexistence (measured by joint life expectancies). That constant consumption profile equivalent is constructed in such a way as to make a representative individual indifferent between, on the one hand, his current situation (with his current consumption profile, current single and joint life expectancies), and, on the other hand, a hypothetical situation with the constant equivalent consumption profile, and with the single and joint life expectancies of a period of reference.

Our empirical application on France (1820-2010) is developed in two stages. First, we construct joint life expectancies using life tables from the Human Mortality Database, while assuming, as a first approximation, that individual

\footnotetext{
${ }^{1}$ Note that the existence of coexistence concerns in real life can be represented by means of various microeconomic models, depending on what motivates coexistence concerns (either self-oriented concerns or altruism) and on how coexistence time is perceived/quantified by individuals. See Section 3 on this.
} 
mortality risks are independent within groups. We show that the improvement of survival conditions over time is associated with a large rise in single life expectancies, and with an even larger rise in joint life expectancies. We also show that the inclusion of monetized gains in coexistence time affects substantially the measurement of economic performance over time. Then, in a second stage, we relax the independence assumption and allow for dependent individual mortality risks using the copula approach (Nelsen 2007). We calculate joint life expectancies using Frank's copula (Frank 1979), and we show that equivalent consumption patterns are robust to introducing risk dependence, since these depend not on the level, but on the variation of joint life expectancy over time.

On the economic side, this paper complements the articles mentioned above (Usher 1973, 1980, and following papers), which developed equivalent income measures, but without taking coexistence time into account. The present study shows that taking coexistence concerns into account contributes to raise the value of improved survival conditions. On the demographic side, some articles, such as Le Bras (1973), studied coexistence by means of probabilities of having a surviving parent or a surviving child, while assuming independent individual mortality risks. More recently, several articles focused on the relation between univariate and multivariate survival (see Frees et al 1996, Denuit et al 2001, Spreeuw and Owadaly 2013). Our paper complements that demographic literature by studying how improvements of joint survival conditions can be taken into account into a measure of standards of living.

The main contribution of this paper is to provide an alternative view on the contribution of improved survival conditions to living standards. Most existing studies aimed at measuring standards of living presupposed that individuals only care about their own survival, and not about the survival of others. Once that strong assumption is relaxed, it appears that the presence of a concern for coexistence with other persons makes the improvement of survival conditions much more valuable. Thus existing studies ignoring concerns for joint survival may have, from that perspective, underestimated the contribution of improved survival conditions to standards of living.

This paper is organized as follows. Section 2 considers an economy where individuals face risk about the duration of their own life, as well as risk about the duration of life of other persons, and proposes joint life expectancy as a measure of the expected coexistence time. Then, Section 3 focuses on the valuation of coexistence, and derives an equivalent consumption measure incorporating the monetized value of variations in coexistence time. As an illustration, Section 4 presents equivalent consumption measures for France (1820-2010), while assuming, as a first approximation, independent individual mortality risks. Then, Section 5 uses the copula approach to examine the robustness of our results to the introduction of dependent individual mortality risks. Section 6 concludes. 


\section{Measuring coexistence time}

Let us consider an economy where individuals face risk about the duration of their life. Individuals know that they will die one day. But they do not know when they will die. The maximal duration of life is denoted by the natural number $T>1$. Each life can take $T+1$ possible durations, from a duration of 0 period to a duration of $T$ periods.

\subsection{Standard life expectancy}

Although the duration of life is, for each individual, unknown, it is possible, at the level of the society as a whole, to calculate the average duration of life for an individual, conditionally on the age-specific probabilities of death prevailing during a particular period. That statistics is the period life expectancy indicator: it consists of the mathematical expectation of the duration of one life, conditionally on the survival probabilities prevailing during a given period.

Figure 1 illustrates the lottery of life faced by a representative individual who faces $T+1$ possible scenarios regarding the duration of his life. Each scenario is characterized by a distinct duration of life. Life expectancy is computed by adding all possible durations of life, each of these being weighted by the probability of occurrence of each duration of life.

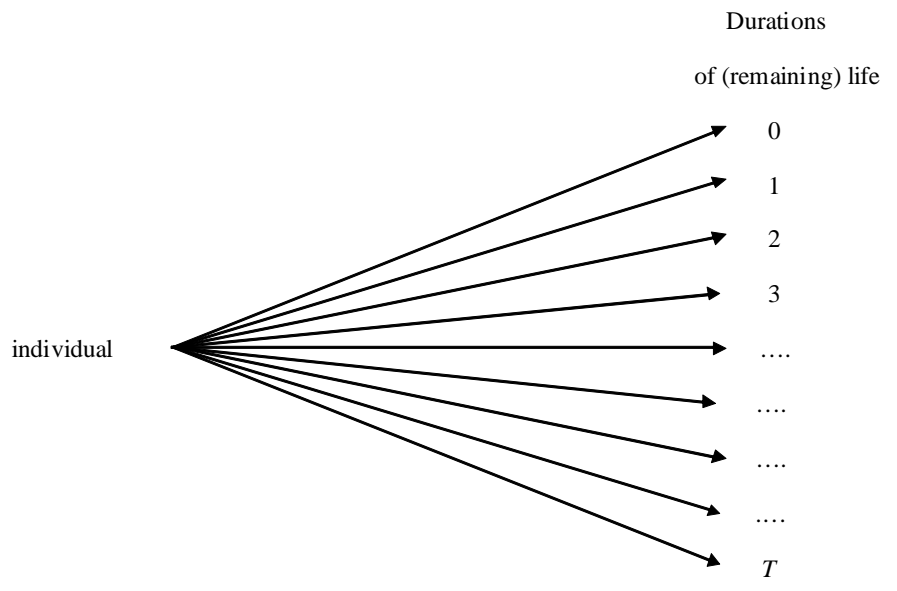

Figure 1: Life as a lottery (I)

If one denotes by $p_{i x}$ the probability of a (remaining) life of duration $x$ for a person $i$, the mathematical expectation of the duration of (remaining) life for a person $i$, denoted by $E\left(L_{i}\right)$, can be written as:

$$
E\left(L_{i}\right)=\sum_{x=0}^{T} p_{i x} \times x
$$


The probability of a life of duration $x$ periods for person $i$ can be written as:

$$
p_{i x}=\prod_{s=0}^{x-1}\left(1-d_{i s}\right) d_{i x}
$$

where $d_{i s}$ is the probability of death at age $s$ for person $i$, conditionally on survival until age $s$. Substituting for $p_{i x}$ in equation (1) allows us to rewrite life expectancy $E\left(L_{i}\right)$ as:

$$
E\left(L_{i}\right)=\sum_{x=0}^{T-1} S_{i x+1}
$$

where $S_{i x} \equiv \prod_{s=0}^{x-1}\left(1-d_{i s}\right)$ is the unconditional probability of survival until age $x$ for person $i$. Life expectancy can be interpreted as a measure of the surface under the survival curve (which plots $S_{i x}$ as a function of $x$ ). ${ }^{2}$

There exist several types of life expectancy. Period life expectancies rely on age-specific probabilities of death prevailing at a particular period (usually one year). On the contrary, cohort life expectancy rely on age-specific probabilities of death prevailing during the entire life of a cohort. Period life expectancy is the most widely used because it can be computed year after year without having to wait for the death of all members of a given cohort.

At this stage, it is important to underline a key feature of period life expectancy statistics. These measure the expected duration of life for some hypothetical "average" person. In reality, the actual duration of life may depend on lots of factors such as, among other things, the genetic background, lifestyles (sleeping patterns, physical activity, etc.), consumption patterns (smoking, drinking, etc.), risk-taking behaviors, preventive behaviors, environmental quality, etc. Period life expectancy statistics only provide some global picture of the survival conditions prevailing on average in a given population.

The major virtue of life expectancy indicators consists in their capacity to synthesize the prevailing survival conditions in one single number. However, life expectancies reflect only a single source of risk in human societies: the risk about one's own survival. Besides that individual longevity risk, humans face many other sources of risk concerning, in particular, the survival of the persons they care about (spouse, children, parents, friends, etc.). The next subsection proposes an indicator taking that alternative source of risk into account.

\subsection{Joint life expectancy}

Recent empirical studies, such as Blanchflower and Oswald (2004), suggest that individuals care a lot about the survival of their spouse. The regressions carried

\footnotetext{
${ }^{2}$ As usual, we assume $S_{i 0}=1$. Note that expression (3) presupposes that a person dying during a year dies at the beginning of that year. Alternatively, if one supposes that a person dying during a year dies, on average, in the middle of that year, (3) becomes:$$
E\left(L_{i}\right)=\sum_{x=0}^{T-1} S_{i x+1}+0.5
$$ 
out by those authors show that an amount of not less than $\$ 100,000$ per year is necessary to compensate someone for widowhood. Such a large compensation reveals that individuals care not only about their own survival, but, also, about the survival of other persons.

Once individuals have a strong concern for others' survival, the representation of life as a lottery in Figure 1 becomes incomplete. Actually, for each scenario concerning one's survival, there exist lots of possible scenarios regarding the survival of other persons. For instance, it is not the same, for an individual, to survive until age 85 with his spouse, or to survive until age 85 while becoming a widow at the age of 70 . Hence the representation of life as a lottery must be modified, in such a way as to account for the various scenarios regarding others' survival. To illustrate this, Figure 2 shows the lottery of life faced by a representative individual $i$ who cares not only about his own survival, but also about the survival of another individual $j$. That alternative representation treats life as a double lottery: for any possible duration of life for person $i$, there exist various possible durations of life for person $j .{ }^{3}$

We can, for each scenario in Figure 2, compute the duration of coexistence between the two individuals. The duration of coexistence for a particular scenario of life equals the minimum of the durations of life for the two individuals. One can regard that duration of coexistence of two individuals as the duration of life for the group of two persons, provided a group disappears as soon as one of its members dies.

Once durations of coexistence are computed under each scenario of the double lottery, we can compute the mathematical expectation of the duration of coexistence. For that purpose, we aggregate all possible durations of coexistence for the two individuals, and we weight each of these by the probability of occurrence of that scenario. The outcome of that calculation consists of the period joint life expectancy of individuals $i$ and $j$. This is the mathematical expectation of the duration of their coexistence, or the average duration of life for that group, conditionally on the survival conditions prevailing during a period.

To illustrate this, let us take for instance two persons $i$ and $j$ of age 25 . Each scenario of the lottery involves one duration of remaining life for person $i$ and one duration of remaining life for person $j$. For each scenario of the lottery, one can compute the duration of remaining coexistence. This is equal to the minimum of the durations of remaining life for the two persons. If, for instance, both persons die at age 28 , the remaining coexistence time equals $\min \{28-25,28-25\}=3$ years. If, on the contrary, person $i$ dies at age 45 , but person $j$ dies at age 42 , the duration of remaining coexistence equals $\min \{45-25,42-25\}=17$ years. Then, once the duration of remaining coexistence is computed for each scenario of the lottery, we can use the probabilities of occurrence of each scenario to calculate the mathematical expectation of the duration of remaining coexistence, that is, the joint life expectancy of individuals $i$ and $j$ (of current age 25). ${ }^{4}$

\footnotetext{
${ }^{3}$ Note that we restrict ourselves here to a double lottery, in which one person cares about his survival and about the survival of another person. But in the real world individuals may care about the survival of more than one other person, implying a more complex lottery.

${ }^{4}$ Similar calculations could be carried out for other groups of different size, including per-
} 


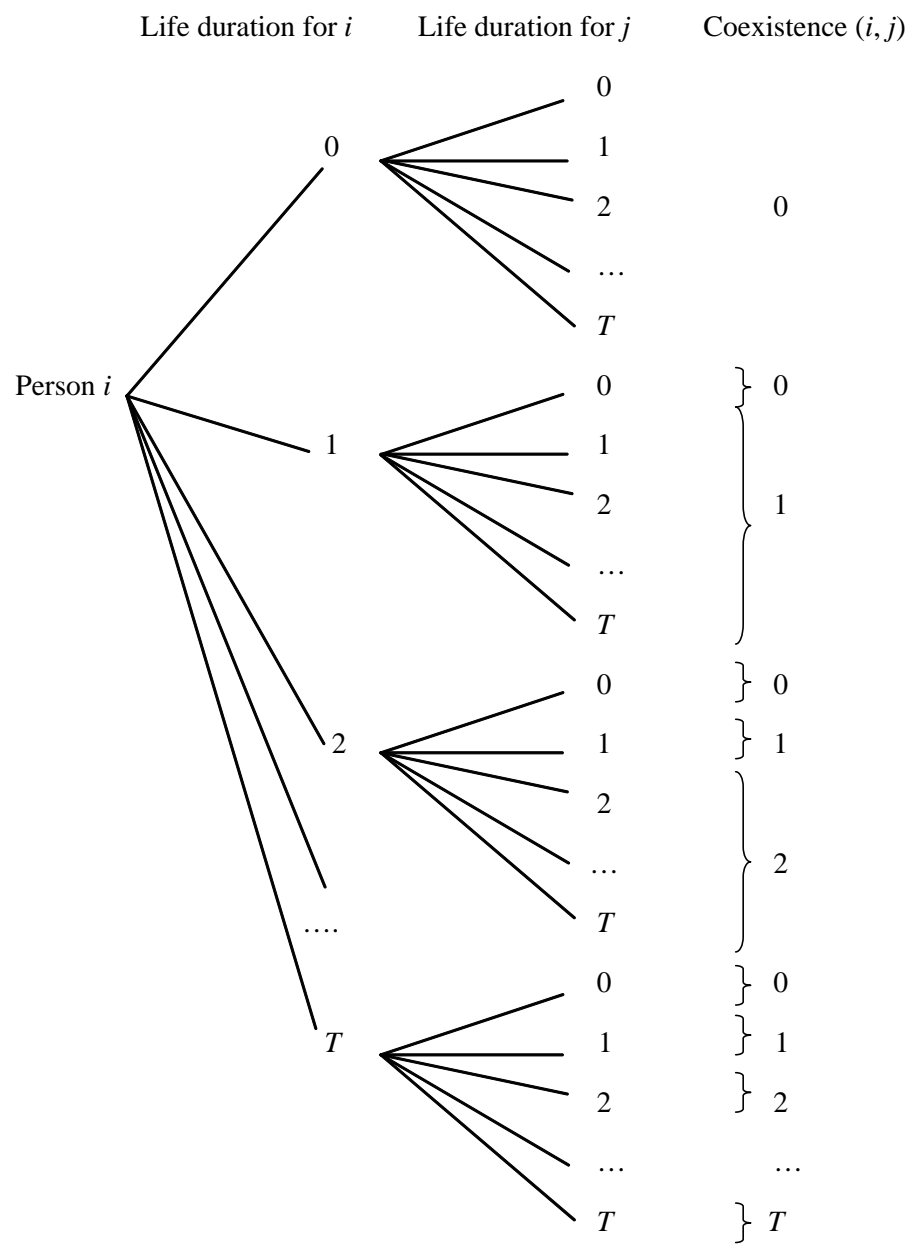

Figure 2: Life as a lottery (II)

More formally, if one denotes by $p_{i j x}$ the probability of (remaining) coexistence of duration $x$ for two persons $i$ and $j$, the joint life expectancy for those two persons, denoted by $E\left(L_{i j}\right)$, can be written as: ${ }^{5}$

$$
E\left(L_{i j}\right)=\sum_{x=0}^{T} p_{i j x} \times x
$$

$p_{i j x}$ depends on the survival conditions faced by persons $i$ and $j$, and on how those survival conditions are related to each other. Alternatively, one can rewrite sons of unequal ages.

${ }^{5}$ While that formula concerns the coexistence of two persons, joint life expectancies can also be defined for a larger number of individuals. 
the joint life expectancy as the surface under the joint survival curve (which plots $S_{i j x}$ as a function of $\left.x\right)$ :

$$
E\left(L_{i j}\right)=\sum_{x=0}^{T-1} S_{i j x+1}
$$

where $S_{i j x+1}$ is the unconditional probability of joint survival until $x$ periods from now, for persons $i$ and $j$. $S_{i j x+1}$ is the probability that both persons $i$ and $j$ are still alive $x$ periods from now.

As for period (single) life expectancies, period joint life expectancies do not, in general, coincide with the actual duration of coexistence for some individuals in reality. It consists, here again, of a statistical object, which measures some aspect of the survival conditions prevailing at a particular period. Period joint life expectancy statistics measure the expected duration of a group of individuals, given the average survival conditions prevailing at a given period. ${ }^{6}$ It tells us, for instance, how many years two persons can expect, given the prevailing survival conditions, to coexist. In real life, coexistence may vary significantly across groups, depending on the characteristics of each group. Hence, what joint life expectancy statistics give us is a global picture of the average joint survival perspectives at some period, in the same way as single life expectancies give us a global picture of survival perspectives at the individual level.

It is also important to stress that the joint life expectancy only measures "coexistence" in a particular sense: it measures "coexistence" only from the perspective of joint survival. If, alternatively, one defined "coexistence" as the quantity of time lived together by two persons in the same spatial neighborhood, then there would exist many other factors than joint survival conditions that would also affect the actual amount of so-defined "coexistence". To illustrate this, take, for instance, the case of a couple. The number of life-years shared by the two members of a couple depends on lots of factors, and not only on the prevailing joint survival conditions. Actually, how long two members of a couple live together depends on the age at marriage, the divorce rates, professional mobility, etc. Similarly, the so-defined "coexistence" between parents and children depends on many other things than joint survival conditions, such as the living arrangements, the duration of education degrees, the age at marriage, the unemployment rate for young people, etc.

Joint life expectancy statistics measure coexistence time in a different sense: they measure how many years two individuals can expect to remain both alive, conditionally on the prevailing average survival conditions. Those measures do not tell us whether those individuals will live in the same house or not, will divorce or not, etc. All those aspects, which contribute to determine "coexistence" in the sense defined above, are not captured by the joint life expectancy, which focuses only on joint survival, independently from the circumstances under which this joint survival will take place. Similarly, single life expectancy statistics do not tell us whether the expected lifetime of an individual will be

\footnotetext{
${ }^{6}$ Alternatively, one may compute cohort joint life expectancies, on the basis of the survival conditions faced within a given cohort.
} 
enjoyed under some particular circumstances, but only how many years one can expect to live. Thus, our joint life expectancy statistics only capture the pure joint survival component of the broad idea of "coexistence".

Having clarified the sense in which joint life expectancies measure the coexistence phenomenon, let us now focus on the relationship between the survival probability of a group and the survival probabilities of its members. The joint survival probability for two individuals $i$ and $j S_{i j x+1}$ (i.e. the probability that both individuals $i$ and $j$ are still alive $x$ periods from now) depends on the survival conditions faced by each individual separately, that is, survival probabilities $S_{i x+1}$ and $S_{j x+1}$. But the relationship between the joint survival probability and individual survival probabilities may take various forms, depending on whether individual mortality risks are dependent or not, and, if so, on the sign (positive or negative) and extent of the dependence.

Positive dependence of individual mortality risks occurs when the premature death for a member of the group raises the probability of premature death for another member of the group. On the contrary, negative dependence prevails when the happening of premature death for a group member reduces the probability of premature death for another member of the group. In those two cases, the relation between joint survival and individual survival is quite complex, and requires specific conceptual tools for the modelling of risk dependence. ${ }^{7}$

Besides those cases, there exists another case: the case of independent mortality risks. When mortality risks are independent, the duration of life for an individual $i$ is unaffected by the duration of life for an individual $j$. Hence, given that the survival chances of a person do not affect the survival chances of any other person in that case, the joint survival probability $S_{i j x+1}$ is equal to the product of the probability that individual $i$ is still alive $x$ periods from now times the probability that individual $j$ is still alive $x$ periods from now:

$$
S_{i j x+1}=S_{i x+1} \times S_{j x+1}
$$

Hence, in that case, the joint life expectancy takes the form:

$$
E\left(L_{i j}\right)=\sum_{x=0}^{T-1}\left(S_{i x+1} \times S_{j x+1}\right)
$$

Thus, when individual mortality risks are independent, the mathematical expectation of the coexistence time between two persons $i$ and $j$ is a sum of products of unconditional survival probabilities until different ages for those two persons.

Assuming that individual mortality risks are independent tends to simplify the analysis of coexistence. This explains why this assumption was made in some demographic studies of joint survival, as in Le Bras (1973 p. 11). Note, however, that this constitutes a significant simplification: in the real world, mortality risks faced by related individuals can be, to some extent, dependent, so that the joint survival probability is not equal to the product of individual survival

\footnotetext{
${ }^{7}$ Section 5 is dedicated to the measurement and valuation of coexistence gains when mortality risks are dependent.
} 
probabilities, but takes a more complex form. Hence, when developing our empirical application, we will, in a first stage, consider the case of independent individual mortality risks as a first approximation (Section 4). Then, in Section 5 , we will relax that assumption and introduce risk dependence.

\section{$3 \quad$ Valuing coexistence time}

In order to measure the value of coexistence time, we will, in the rest of this paper, rely on equivalent consumption measures, in line with the equivalent income approach. That method, which has become increasingly used in the literature aimed at valuing gains in life expectancy over time, is presented in Section 3.1. Section 3.2 extends it to the valuation of gains in coexistence time.

\subsection{An equivalent consumption approach}

A major difficulty raised by the inclusion of life-years in indicators of economic performance consists in the selection of adequate weights to represent the contribution of longevity gains relative to other determinants of well-being. This weighting problem arises because living standards are multidimensional. The equivalent income/consumption approach deals with the weighting problem by starting from (representative) preferences on hypothetical situations defined in terms of all dimensions of well-being under study. Those preferences are then used to construct an equivalent income/consumption aimed at measuring, in monetary terms, the well-being associated to some particular living conditions. The equivalent income/consumption is defined as the hypothetical income/consumption such that, if combined with reference levels for the other dimensions of well-being under study, it would bring the same well-being level as under the current income/consumption and the current living conditions.

In the context of the valuation of longevity gains, one can include longevity gains in a monetary measure of welfare by defining a constant consumption profile equivalent, that would, by construction, make a representative agent indifferent between, on the one hand, his current situation (with current constant consumption profile and life expectancy), and, on the other hand, a hypothetical situation with the equivalent consumption profile and the life expectancy of reference (usually the one prevailing at a base year).

Denoting by $U\left(\mathbf{c}_{i}, \mathbf{S}_{i}\right)$ the utility function representing individual $i$ 's preferences over lotteries of life defined as a pair $\left(\mathbf{c}_{i}, \mathbf{S}_{i}\right)$, where $\mathbf{c}_{i}$ is a vector of dimension $T+1$, whose entries consist of constant consumption levels at each (potential) period of life, while $\mathbf{S}_{i}$ is a vector of dimension $T+1$, whose entries consist of unconditional survival probabilities to the different ages of life, one can define the constant consumption profile equivalent $\hat{\mathbf{c}}_{i}$ in the following way:

$$
U\left(\mathbf{c}_{i}, \mathbf{S}_{i}\right)=U\left(\hat{\mathbf{c}}_{i}, \overline{\mathbf{S}}_{i}\right)
$$

where $\overline{\mathbf{S}}_{i}$ represents the reference survival conditions. 
The constant consumption profile equivalent $\hat{\mathbf{c}}_{i}$ captures, by construction, the welfare gains associated with an improvement in survival conditions. To see this, note first that if the actual survival conditions are equal to the reference survival conditions (i.e. if $\mathbf{S}_{i}=\overline{\mathbf{S}}_{i}$ ), then the current consumption profile and the equivalent consumption profiles are equal: $\hat{\mathbf{c}}_{i}=\mathbf{c}_{i}$. However, if the actual survival conditions are better than the reference survival conditions, i.e. if $\overline{\mathbf{S}}_{i} \ll \mathbf{S}_{i}$, we have $\mathbf{c}_{i} \ll \hat{\mathbf{c}}_{i}$, reflecting the improvement in the quality of life.

Assuming that (i) individual preferences satisfy the expected utility hypothesis (i.e. preferences on lotteries are represented by a weighted sum of utilities associated to the scenarios of those lotteries, with weights corresponding to the probability of occurrence of each scenario), (ii) lifetime welfare is a discounted sum of temporal welfare levels (with some constant pure time preference factor $\beta$ ), (iii) temporal welfare takes the form $\frac{c_{i}^{1-\gamma}}{1-\gamma}+\alpha$, we can represent individual $i$ 's preferences by:

$$
U\left(\mathbf{c}_{i}, \mathbf{S}_{i}\right)=\sum_{s=0}^{T-1} \beta^{s} S_{i s+1}\left(\frac{c_{i}^{1-\gamma}}{1-\gamma}+\alpha\right)
$$

From which we can write the equivalent consumption flow $\hat{c}_{i}$ (i.e. the entry of the constant equivalent profile $\hat{\mathbf{c}}_{i}$ ) as satisfying the following equality:

$$
\sum_{s=0}^{T-1} \beta^{s} S_{i s+1}\left(\frac{c_{i}^{1-\gamma}}{1-\gamma}+\alpha\right)=\sum_{s=0}^{T-1} \beta^{s} \bar{S}_{i s+1}\left(\frac{\hat{c}_{i}^{1-\gamma}}{1-\gamma}+\alpha\right)
$$

From which it follows that the equivalent consumption flow $\hat{c}_{i}$ is:

$$
\hat{c}_{i}=\left\{(1-\gamma)\left[\left(\frac{\sum_{s=0}^{T-1} \beta^{s} S_{i s+1}\left(\frac{c_{i}^{1-\gamma}}{1-\gamma}+\alpha\right)}{\sum_{s=0}^{T-1} \beta^{s} \bar{S}_{i s+1}}\right)-\alpha\right]\right\}^{\frac{1}{1-\gamma}}
$$

The equivalent consumption flow $\hat{c}_{i}$ is such that, if enjoyed every year while facing the survival conditions of reference, this would make the representative agent indifferent between that hypothetical situation and his current situation (with current consumption profile and survival probabilities). The equivalent consumption flow allows us to incorporate, within an extended monetary measure of economic performance, variations in survival conditions with respect to reference survival conditions. Expression (11) shows how preferences, through the parameters $\alpha, \beta$ and $\gamma$, affect the shape of the constant equivalent consumption level $\hat{c}_{i}$. The gap between the actual and the equivalent consumption levels depends on the differential between the existing survival conditions and the survival conditions of reference.

The monerary equivalent method was used, with several amendments, in Williamson (1984), Crafts (1997), Costa and Steckel (1997), Sandberg and Steckel (1997), Nordhaus (2003), Becker et al (2005), Murphy and Topel (2006), Hall and Jones (2007) and Fleurbaey and Gaulier (2009). Those studies highlighted that the measurement of economic performance over time is strongly 
affected by the inclusion of variations in survival conditions. In the following, we propose to extend that approach to the inclusion of variations in joint survival conditions.

\subsection{Equivalent consumption under coexistence concerns}

When an individual cares about coexistence with $M>0$ other individuals, his utility function depends not only on his consumption and on his own survival chances, but also on how long he expects to coexist with each of those $M$ individuals. This latter determinant of his well-being can be measured by the joint life expectancies with those persons. Since joint life expectancies depend on the survival conditions faced by each of those persons (because $S_{i j x+1}$ is a function of $S_{i x+1}$ and $S_{j x+1}$ ), the well-being of our representative individual depends now on the survival conditions faced by the $M$ persons of interest. ${ }^{8}$

In that context, we can redefine the constant consumption profile equivalent, as the hypothetical constant consumption profile that would, by construction, make a representative agent indifferent between, on the one hand, his current situation, with his current consumption and the current survival conditions (both for himself and for the $M$ persons he cares about), and, on the other hand, a hypothetical situation with the constant equivalent consumption profile and the survival conditions of reference (both for himself and the $M$ persons).

If one denotes by $\tilde{U}\left(\mathbf{c}_{i}, \mathbf{S}_{i}, \mathbf{S}_{1}, \ldots, \mathbf{S}_{M}\right)$ the utility function of individual $i$ that represents his preferences over lotteries involving different durations of life for him as well as for the $M$ other persons, the constant equivalent consumption profile $\hat{\mathbf{c}}_{i}$ now satisfies the condition:

$$
\tilde{U}\left(\mathbf{c}_{i}, \mathbf{S}_{i}, \mathbf{S}_{1}, \ldots, \mathbf{S}_{M}\right)=\tilde{U}\left(\hat{\mathbf{c}}_{i}, \overline{\mathbf{S}}_{i}, \overline{\mathbf{S}}_{1}, \ldots, \overline{\mathbf{S}}_{M}\right)
$$

where $\overline{\mathbf{S}}_{i}, \overline{\mathbf{S}}_{1}, \ldots, \overline{\mathbf{S}}_{M}$ are the unconditional survival probabilities of reference for persons $i$ and for the $M$ persons. Under that formulation, the constant equivalent consumption profile captures not only the variations, with respect to the survival conditions of reference, in the survival conditions faced by individual $i$, but also the variations in the survival conditions faced by the $M$ other persons.

Assuming that individual $i$ 's preferences satisfy conditions (i) and (ii), and replacing (iii) by assumption (iv), according to which temporal welfare equals $\frac{c_{i}^{1-\gamma}}{1-\gamma}+\alpha+\sum_{q=1}^{N} \delta_{q}$ in case of coexistence with $N$ persons (out of the $M$ persons he cares about), the utility function $\tilde{U}\left(\mathbf{c}_{i}, \mathbf{S}_{i}, \mathbf{S}_{1}, \ldots, \mathbf{S}_{M}\right)$ can be written as:

$$
\tilde{U}\left(\mathbf{c}_{i}, \mathbf{S}_{i}, \mathbf{S}_{1}, \ldots, \mathbf{S}_{M}\right)=\sum_{s=0}^{T-1} \beta^{s} S_{i s+1}\left(\frac{c_{i}^{1-\gamma}}{1-\gamma}+\alpha\right)+\sum_{q=1}^{M} \delta_{q} \sum_{s=0}^{T-1} \beta^{s} S_{i q s+1}
$$

where $\delta_{q}$ is the intensity of individual $i$ 's coexistence concerns with person $q$. The function $\tilde{U}\left(\mathbf{c}_{i}, \mathbf{S}_{i}, \mathbf{S}_{1}, \ldots, \mathbf{S}_{M}\right)$ can be decomposed in two components: on

\footnotetext{
${ }^{8}$ The form of the relation between the probabilities of joint survival (and, hence, the joint life expectancy) and individual survival probabilities may vary, depending on how dependent individual survival processes are. See Section 5 on this.
} 
the one hand, the expected welfare from consumption of goods and services (first sum of terms), which depends on individual $i$ 's survival probabilities; on the other hand, the expected welfare from coexistence with the $M$ persons of interest (second sum of terms), which depends on the joint life expectancy of individual $i$ with each of those persons of interest. ${ }^{9}$

The additive structure of $\tilde{U}\left(\mathbf{c}_{i}, \mathbf{S}_{i}, \mathbf{S}_{1}, \ldots, \mathbf{S}_{M}\right)$ implies that the welfare gain from coexisting with one person is independent from the welfare gain from coexisting with other persons. Note that, in the real world, it may be the case that the welfare derived from coexistence with a person depends on the presence of some other person. However, there is, in general, no obvious way to relate the welfare gains from coexistence with different persons. In that context, assuming an additive structure is a plausible first-order approximation.

On the basis of $\tilde{U}\left(\mathbf{c}_{i}, \mathbf{S}_{i}, \mathbf{S}_{1}, \ldots, \mathbf{S}_{M}\right)$, we can write the equivalent consumption flow $\tilde{c}_{i}$ (i.e. the entry of the constant equivalent profile $\hat{\mathbf{c}}_{i}$ ) as satisfying:

$$
\begin{aligned}
& \sum_{s=0}^{T-1} \beta^{s} S_{i s+1}\left(\frac{c_{i}^{1-\gamma}}{1-\gamma}+\alpha\right)+\sum_{q=1}^{M} \delta_{q} \sum_{s=0}^{T-1} \beta^{s} S_{i q s+1} \\
= & \sum_{s=0}^{T-1} \beta^{s} \bar{S}_{i s+1}\left(\frac{\tilde{c}_{i}^{1-\gamma}}{1-\gamma}+\alpha\right)+\sum_{q=1}^{M} \delta_{q} \sum_{s=0}^{T-1} \beta^{s} \bar{S}_{i q s+1}
\end{aligned}
$$

Isolating the equivalent consumption flow $\tilde{c}_{i}$, one obtains:

$$
\tilde{c}_{i}=\left\{(1-\gamma)\left[\left(\frac{\sum_{s=0}^{T-1} \beta^{s} S_{i s+1}\left(\frac{c_{i}^{1-\gamma}}{1-\gamma}+\alpha\right)+\sum_{q=1}^{M} \delta_{q} \Delta_{q}}{\sum_{s=0}^{T-1} \beta^{s} \bar{S}_{i s+1}}\right)-\alpha\right]\right\}^{\frac{1}{1-\gamma}}
$$

where $\Delta_{q} \equiv \sum_{s=0}^{T-1} \beta^{s} S_{i q s+1}-\sum_{s=0}^{T-1} \beta^{s} \bar{S}_{i q s+1}$.

As in the baseline model, $\tilde{c}_{i}$ depends on individual $i$ 's survival chances, and on preference parameters $\alpha, \beta$ and $\gamma$. However, under coexistence concerns, $\tilde{c}_{i}$ depends also on the joint survival chances of individual $i$ with each of the $M$ persons of interest, and on the preference parameters $\delta_{q}$, which capture the welfare gains from coexistence with each of those persons. As a consequence, $\tilde{c}_{i}$ captures not only the variations in life expectancy for person $i$, but also the gains in joint life expectancy with the persons of interest.

\footnotetext{
${ }^{9}$ The utility function is assumed to exhibit self-oriented coexistence concerns: according to that function, individuals care about the survival of other persons only for themselves, without caring about the well-being of those other persons. It should be stressed here that this utility function does not constitute the only way to represent coexistence concerns. As an alternative to self-oriented coexistence concerns, we could have represented coexistence concerns by means of a utility function exhibiting altruism (individuals would be interested in the well-being of others, and, hence, in the survival of others).
} 


\section{An illustration with French data (1820-2010)}

Let us now illustrate the above discussions in the light of the example of France (1820-2010). For that purpose, we will proceed in two stages. Section 4.1 presents joint life expectancy statistics for France, and discusses the evolution of the generational overlap over time. Section 4.2 proposes to quantify the contribution of improved joint survival conditions to living standards, under different scenarios regarding the structure of coexistence concerns.

Throughout this section, we will first focus, for the sake of simplicity, on the case where individual mortality risks are independent, so that the joint life expectancies can be written as a sum of products of individual unconditional survival probabilities. Then, Section 5 will examine the robustness of our results to introducing mortality risk dependence by means of the copula approach.

\subsection{Joint life expectancies}

The demographic data that we use are the lifetables from the Human Mortality Database for France (1816-2010). ${ }^{10}$ In order to give a general view of the evolution of survival conditions over that period, Figure 3 presents the patterns of life expectancy at birth for men and women over that period. Life expectancy has strongly grown: the expected duration of life was, in 1816, about 39 years for men and about 41 years for women, it is nowadays about 78 years for men and 85 years for women. The three drops coincide with the French Commune (1871), the First and the Second World War.

Given the observed improvement of survival conditions, one expects that the duration of coexistence between individuals must have increased too. However, without any further calculations, it is hard to know to what extent coexistence time has grown over time. Actually, as we will show below, the precise extent to which coexistence has grown depends on the particular age of the individuals whose coexistence is considered.

Let us take, as a first case, the coexistence of a man and a woman of age 25 years in France (Figure 4). During the 19th century, the joint life expectancy of a man and a woman of age 25 was relatively stable, and equal to about 28 years. However, there has been a strong growth in coexistence time during the 20th century. In 2010, a man and a woman of age 25 can expect to coexist about half a century. Note also, still on Figure 4, that the expected coexistence has decreased strongly during the French Commune, the First and the Second World Wars. If one interprets the pair of a man and a woman as a couple, those drops show that, in times of conflict, a significant part of the population falls in widowhood, implying a decline in the average coexistence time for couples. ${ }^{11}$

\footnotetext{
${ }^{10}$ Sources: The Human Mortality Database (2013), University of California, Berkeley (U.S.), Max Planck Institute for Demographic Research (Germany). Available online at: http://www.mortality.org. Note that Section 4.1 presents demographic data over 1816-2010, whereas our income data only cover the period 1820-2010. Hence, demographic data for years 1816-1819 will not be used when computing consumption equivalents (Section 4.2).

${ }^{11}$ Note that, if one carries out the same computation exercise for a pair composed of a man and a woman of age 50 years, one finds a similar pattern: stagnation of the joint life
} 


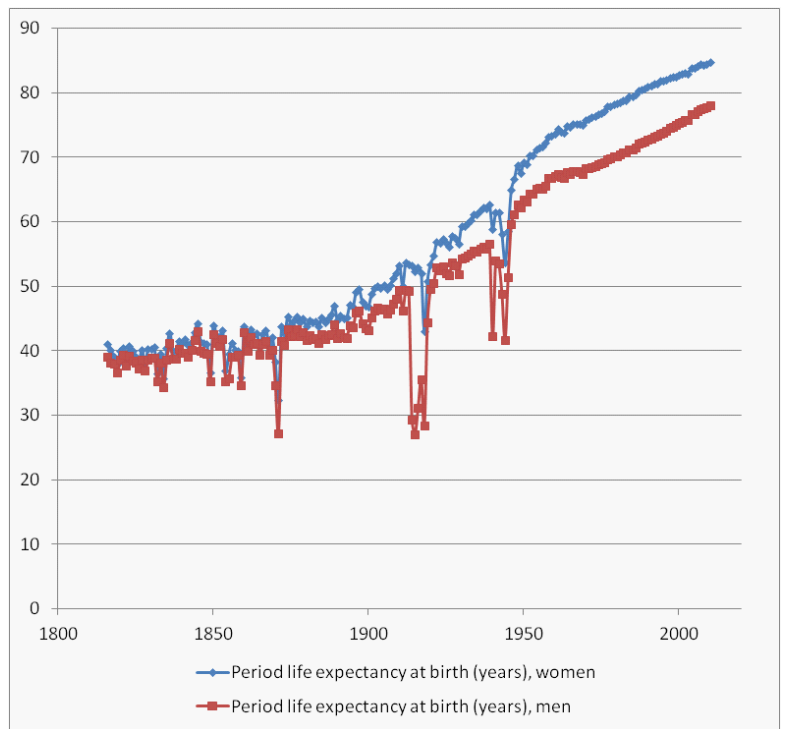

Figure 3: (Period) life expectancy at birth in France, 1816-2010, women and men

When interpreting Figure 4, it should be stressed that joint life expectancies quantify coexistence only from the perspective of joint survival. Those measures quantify the expected time during which both a male and a female of some ages will remain alive. But there is no concern here for divorce, living arrangements, or other factors affecting coexistence in a broader sense.

Joint life expectancies can also be used to measure the duration of coexistence for persons who belong to different generations, that is, the overlap between generations. Figure 5 shows the joint life expectancy of a woman of age 25 with a newborn boy over 1816-2010. The expected duration of coexistence for those persons has been multiplied by a factor (almost) equal to 3 , from about 22 years in 1816 to about 60 years in 2010. The rise in the joint life expectancy is here larger than the rise in the life expectancy of the two persons taken separately. Actually, life expectancy has, over that period, doubled (approximately), whereas the joint life expectancy was multiplied by 3 . If one interprets Figure 5 as showing the expected duration of coexistence for a young mother with her newborn boy, it follows that the average size of the overlap between two successive generations has grown strongly during the 20th century.

expectancy during the 19th century, and strong growth during the second part of the 20th century. While a man and a woman of age 50 could expect to coexist about 15 years in the 19 th century, their expected duration of coexistence is now equal to 28 years. 


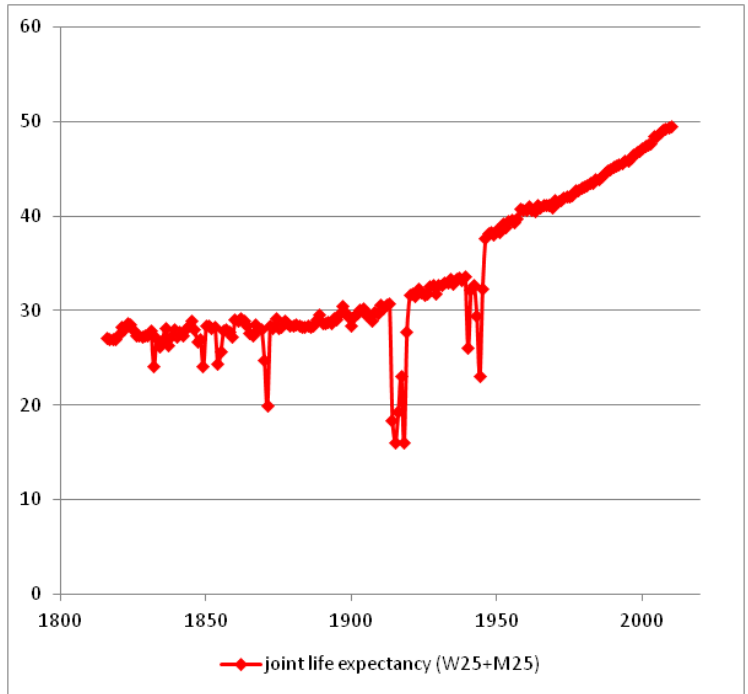

Figure 4: (Period) joint life expectancy for a woman and a man of age 25, France (1816-2010)

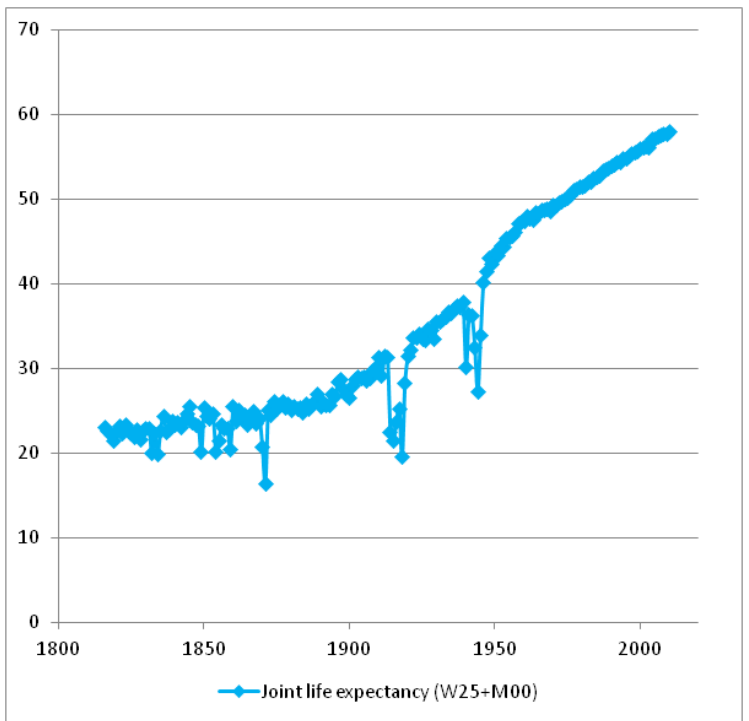

Figure 5: (Period) joint life expectancy for a woman of age 25 and a newborn boy, France

(1816-2010)

In a similar vain, Figure 6 shows the joint life expectancy for a woman of age 50 with a newborn boy. Whereas coexistence between them was about 15 years 
during the 19th century, this is today above 35 years. If one assumes generations of 25 years, that joint life expectancy can be interpreted as the average size of the overlap between two generations separated by an intermediate generation. Coexistence with a grandmother lasted, on average, less than 15 years during the 19th century. Nowadays, it lasts more than 35 years.

Note, here again, that joint life expectancy measures coexistence only in a particular sense, that is, from the perspective of joint survival. Many other factors can affect the size of the overlap between generations. For instance, the recent tendency towards the postponement of births starting in the 1970s (see Gustafsson 2001) may tend to reduce, to some extent, the contribution of the rise in joint life expectancies to the overlap between generations. However, if we consider the overlap of two successive generations (Figure 5), the postponement of births affects the overlap in a way that is, over the entire period considered, likely to be far less sizeable than the impact of improved joint survival conditions. It is only for the overlap of non successive generations, as on Figure 6, that the postponement of births could have a more significant impact on the generational overlap (in case of repeated postponement of births at each generation).

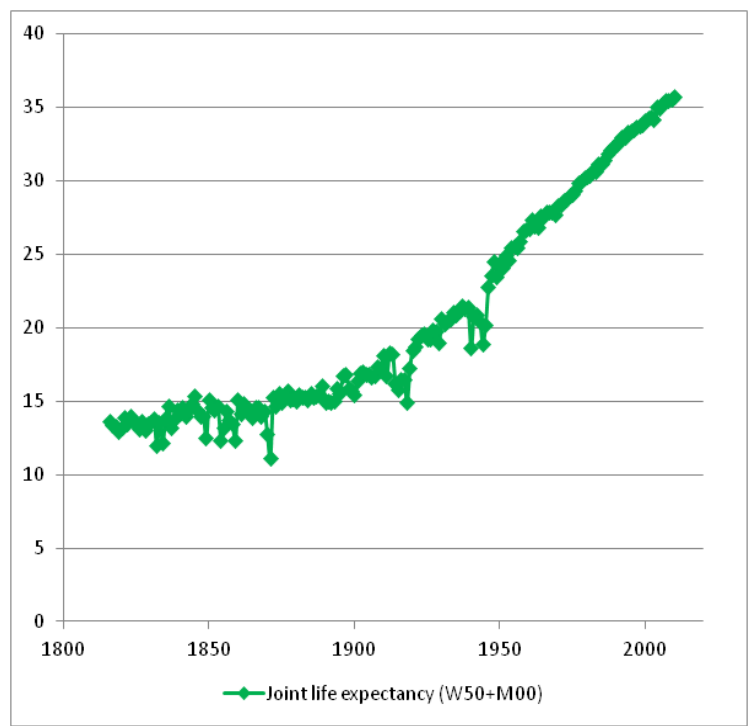

Figure 6: (Period) joint life expectancy for a woman of age 50 and a newborn boy, France

(1816-2010)

An alternative way to measure the evolution of coexistence time consists of joint survival curves. Those curves are the equivalent, for the measure of coexistence time, of standard survival curves focusing on the lifetime of a single individual. A joint survival curve indicates the probability that a group of 
individuals of some particular age and gender achieves a particular duration of existence, conditionally on age-specific probabilities of survival.

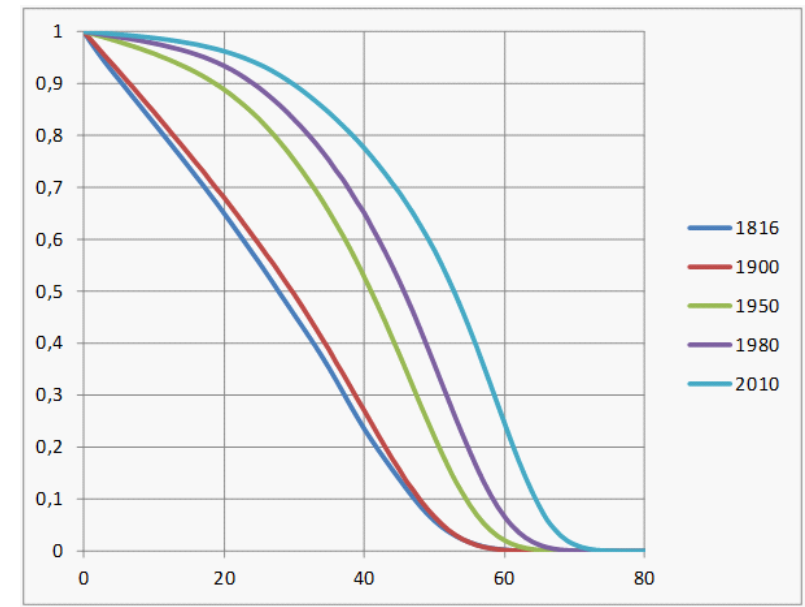

Figure 7: Joint survival curves (period) for a man and a woman aged 25 .

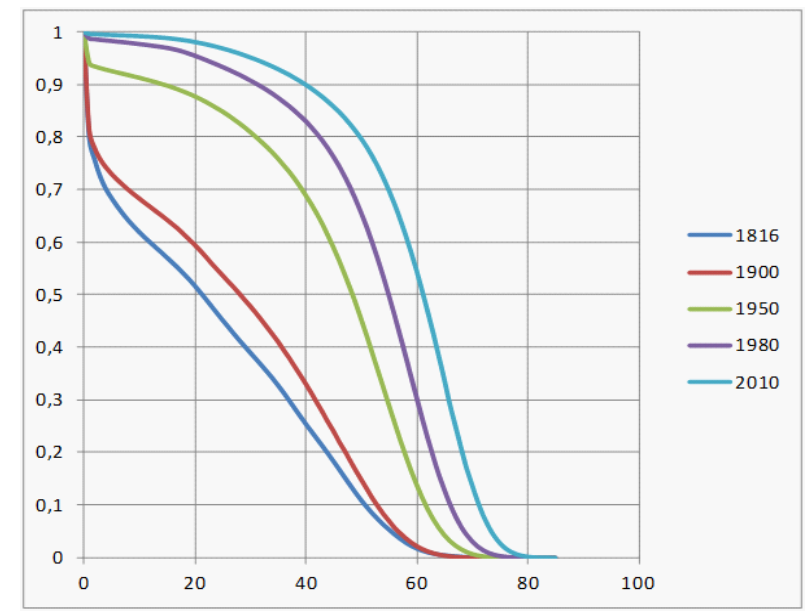

Figure 8: Joint survival curves (period) for a woman aged 25 and a newborn boy.

As an illustration, Figure 7 shows the evolution of joint survival curves in the case of groups composed of a man and a woman of age 25. On the basis of age-specific mortality rates prevailing in 1816, only $23.5 \%$ of pairs composed of a man and a woman of age 25 would still be complete 40 years later, whereas $76.5 \%$ of those pairs would have, during the next 40 years, suffered from the 
death of at least one of their members. But if we focus on the survival conditions prevailing in 2010, the proportion of pairs still complete 40 years later is equal to $77.5 \%$, that is, more than three times larger than in 1816. The evolution of coexistence time over the last two centuries appears even stronger once one focuses on the proportion of pairs of individuals still complete after a period of 60 years. That proportion has grown from 2 out of 1000 on the basis of 1816 survival conditions, to 245 out of 1000 on the basis of 2010 survival conditions.

In a similar vein, Figure 8 shows the evolution of joint survival curves for a pair composed of a woman of age 25 and a new-born boy. Here again, the gains in terms of coexistence time are substantial. Whereas only $25.5 \%$ of those pairs remained complete 40 years later on the basis of 1816 survival conditions, that proportion grew to $33 \%$ in 1900, to $69 \%$ in 1950, and reaches $90 \%$ in 2010 . If one interprets those pairs as pairs composed of a mother and her child, the latter number means that, conditionally on age-specific probabilities of death prevailing in 2010, $90 \%$ of children will coexist at least 40 years with their mother. That figure is about 4 times larger than in 1816.

Note that Figure 8 shows the evolution of joint survival under a given, fixed age gap between the woman and the boy, equal to 25 years. This fixed age gap constitutes a simplification of reality. In particular, the recent tendency towards the postponement of births has increased the average age gap between mothers and sons (Gustafsson 2001). However, this trend is recent in comparison with the long-lasting improvement in survival conditions. Moreover, the rise in the age gap does not suffice to fully counterbalance the large gains achieved in terms of joint survival.

\subsection{Equivalent consumptions}

In this section, we calculate the value of coexistence years by using the method of consumption equivalents that was presented in Section 3. That method can hardly be illustrated geometrically, since the number of dimensions under study (i.e. consumption per year and survival conditions per year) is too large. However, for the sake of illustration, we can represent geometrically the construction of monetary equivalents by focusing on a simple two-dimensional case, involving only income and life expectancy. That case is illustrated on Figure 9, with the example of France (1820-2010). ${ }^{12}$ Figure 9 shows the evolution of France in the (income, life expectancy) space. Provided one draws an indifference map in that space, it is possible to compute an equivalent income for each year, under some particular baseline survival conditions. ${ }^{13}$

If, for instance, one chooses the life expectancy prevailing in 1950 as a reference, one can, for each year under study, compute the hypothetical income level

\footnotetext{
12 The income figures are GDP per capita expressed in International Geary-Khamis dollars (1990). Sources: The Maddison Project: http://www.ggdc.net/maddison/maddisonproject/home.htm. Life expectancy figures come from the Human Mortality Database (2013).

${ }^{13}$ The indifference map on Figure 9 is drawn in an arbitrary way. The next subsection explores the construction of a more realistic indifference map on the basis of the empirical literature on money/risk and risk/risk trade-offs.
} 
that would maintain the representative agent on the same indifference curve, while facing the 1950 survival conditions. ${ }^{14}$ Figure 9 illustrates the computation of the equivalent income for year 1972. The equivalent income is obtained by moving along the indifference curve passing through the 1972 point, until one reaches the 1950 life expectancy level.

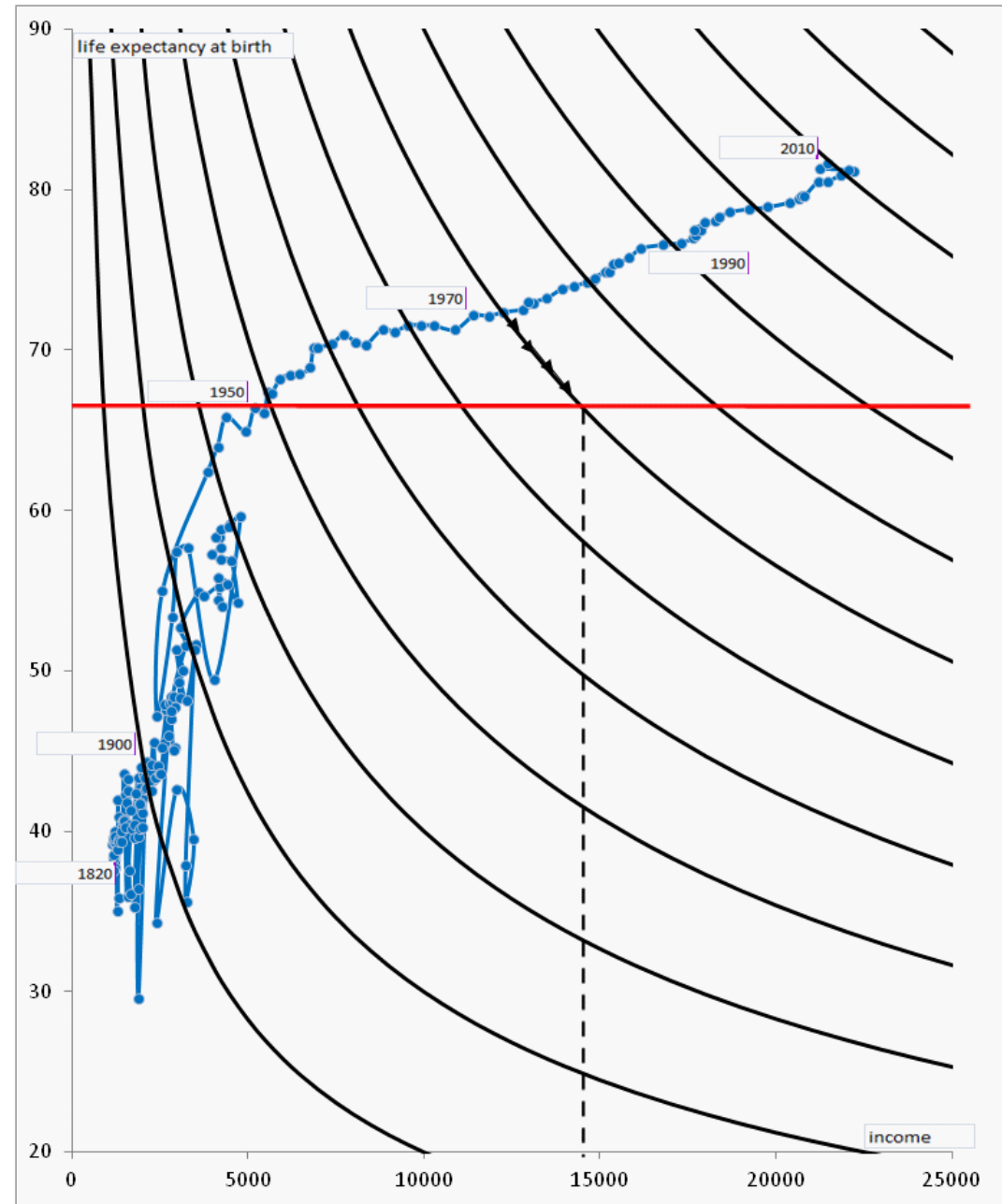

Figure 9: Construction of the equivalent income for year 1972 in France.

This section, which computes constant consumption profile equivalents, carries out the same kind of computation of monetary equivalents, but in a different

\footnotetext{
${ }^{14}$ The reference survival conditions - here the ones prevailing in 1950 - were chosen arbitrarily. A similar construction could be carried out under alternative reference survival conditions.
} 
space, including more dimensions (consumption per year and survival conditions per year), as presented in Section 3. The major difficulty raised by the equivalent consumption approach consists of drawing the indifference map in the space under study. Obviously, given that both consumptions and survival conditions are in general desirable goods, indifference curves must be decreasing. Moreover, one expects also that very short lives with high consumptions and very long lives with low consumptions must be dominated, in welfare terms, by lives with intermediate duration and intermediate consumptions. As a consequence, it is also reasonable to expect that indifference curves are convex. Having stressed this, one needs additional information to be able to draw the indifference map. The next subsection shows how one can draw such indifference maps on the basis of empirical studies on money-risks and risks-risks trade-offs.

\subsubsection{Calibration of preference parameters}

In our model, the knowledge of preference parameters $\alpha, \beta, \gamma$ and $\delta_{K}$ would allow us to draw an indifference map in a space including, as dimensions, consumptions at different ages as well as individual and joint survival probabilities.

For the sake of presentation, we will focus on the case of a representative agent of age $25 .^{15}$ When considering the calibration of preferences, it is clear that there exists a strong heterogeneity in real life, concerning both the strength and direction of coexistence concerns. We will consider here four distinct calibrations, each of these corresponding to a more or less dense network of welfare interdependencies (i.e. a more or less high number $M$ of persons of interest):

1. Case $M 0:$ Absence of welfare interdependencies $(M=0)$

2. Case $M 3$ : Weak interdependencies $(M=3)$

3. Case $M 6$ : Strong interdependencies $(M=6)$

4. Case $M 9$ : Extended interdependencies $(M=9)$

Case $M 0$, where individuals only care about their own survival, is implausible, but will be used as a benchmark. Regarding cases $M 3$ to $M 9$, we assume that social interdependencies are uniformly distributed in terms of generations. In other words, the persons whose survival matters for an individual of age 25 will be supposed to be of ages 0,25 and 50 years in equal proportions. ${ }^{16}$

The calibration of parameters $\beta$ and $\gamma$ can be based on the existing literature. The parameter $\beta$, which reflects pure time preferences, takes in general a value

\footnotetext{
${ }^{15}$ The reason why we do not consider lower ages is that our consumption data do not cover ages inferior to 25 years (see the Appendix).

${ }^{16}$ In the case of society $M 3$, it is assumed that the representative individual cares about the survival of a spouse, of a child and of a parent. In the case of society $M 6$, it is assumed that the representative agent cares about the survival of one spouse, of two parents and of two children. Finally, in the case of society $M 9$, it is assumed that the representative individual cares about the survial of one spouse, two parents and two children, as well as of one person of his generation, one person of the previous generation and one person of the next generation.
} 
that is consistent with a quarterly discount factor equal to 0.99 (see de la Croix and Michel 2002). In our model, where each period lasts one year, the adequate value of $\beta$ is equal to $(0.99)^{4}=0.96$. As far as the calibration of $\gamma$ is concerned, empirical studies surveyed in Browning et al (1999) lead to values close to 0.85. Following Blundell et al (1994), we will use $\gamma=0.83$.

Regarding the calibration of parameters $\alpha$ and $\delta_{K}$, we will rely on the literature on money/risk trade-offs. The literature on the value of a statistical life (VSL) - i.e. the shadow price of a reduction of the risk of death per unit of risk - is broad, and includes studies of two distinct types: revealed preferences studies (focusing on how individuals solve the money/risk trade-off on existing markets) and stated preferences studies (asking to individuals their willingness to pay - WTP - or their willingness to accept - WTA - for small variations in the risk of death). ${ }^{17}$ Despite significant variations across methods (the WTA being generally larger than the WTP for an equal variation of risk), VSL studies all showed that reductions of the risk of death are highly valued (see Aldy and Viscusi 2003). According to Miller (2000), the VSL amounts to between 120 and 180 times the GDP per capita. This indicates that individuals strongly value reductions in the risk of death, even though VSL estimates vary according to variables such as income, health status and age (see Cropper et al 2011).

Empirical estimates of the VSL can be used to calibrate parameters $\alpha$ and $\delta_{K}$. For that purpose, let us assume, as a first approximation, that individual mortality risks are independent. ${ }^{18}$ If one defines, like Jones-Lee (1991), the VSL as the average marginal rate of substitution between consumption and the risk of death within the population, the VSL can be written, in our model with homogeneous population, as:

$$
\left.\frac{\partial c_{0 t}}{\partial d_{I 0 t}}\right|_{U(\cdot)=\bar{U}}=-\frac{\frac{\partial U(\cdot)}{\partial d_{I I t}}}{\frac{\partial U(\cdot)}{\partial c_{0 t}}}=\frac{\left[\begin{array}{l}
\sum_{i=0}^{T-1} \frac{\beta^{i} S_{I i+1 t}\left(\frac{c_{i}^{1-\gamma}}{1-\gamma}+\alpha\right)}{\left(1-d_{I 0 t}\right)} \\
+\sum_{K=1}^{M} \delta_{K} \sum_{i=0}^{T-1} \frac{\beta^{i} S_{I K i+1 t}}{\left(1-d_{I 0 t}\right)}
\end{array}\right]}{\left(1-d_{I 0 t}\right)\left(c_{0 t}\right)^{-\gamma}}
$$

where $S_{I i+1 t}$ denotes the probability of survival for the representative agent $I$ until period $i+1$ on the basis of mortality tables prevailing at time $t, d_{I 0 t}$ denotes the probability of death in the first period for the representative individual $I$ on the basis of mortality tables prevailing at time $t$, while $S_{I K i+1 t}$ denotes the probability of joint survival for the representative individual $I$ with individual $K$ until period $i+1$ on the basis of mortality tables prevailing at time $t .{ }^{19}$

In the case $M 0$, where there is no interest for coexistence (i.e. $\delta_{K}=0$ for

\footnotetext{
${ }^{17}$ On revealed preferences studies, see the survey by Viscusi (1998). On stated preferences studies, see Johansson (1995). Stated preferences studies are subject to framing effects (see Andersson et al 2013 for recent evidence of time framing effects).

${ }^{18}$ The calibration of preference parameters under dependent mortality risks is examined in Section 5 .

${ }^{19}$ Survival probabilities are taken from the Human Mortality Database. For simplicity, we take survival probabilities for the total population (men and women).
} 
all $K$ ), the above expression can be simplified to:

$$
\left.\frac{\partial c_{0 t}}{\partial d_{I 0 t}}\right|_{U(\cdot)=\bar{U}}=-\frac{\frac{\partial U(\cdot)}{\partial d_{I 0 t}}}{\frac{\partial U(\cdot)}{\partial c_{0 t}}}=\frac{\sum_{i=0}^{T-1} \frac{\beta^{i} S_{I i+1 t}\left(\frac{c_{i}^{1-\gamma}}{1-\gamma}+\alpha\right)}{\left(1-d_{I 0 t}\right)}}{\left(1-d_{I 0 t}\right)\left(c_{0 t}\right)^{-\gamma}}
$$

From that expression, it is possible, for empirical estimates of parameters $\beta$ and $\gamma$ and for empirical estimates of the VSL, to extrapolate a value for preference parameter $\alpha$ from mortality tables and consumption profiles. ${ }^{20}$ To see this, note that isolating $\alpha$ yields:

$$
\alpha=\frac{V S L \times\left(1-d_{I 0 t}\right)\left(c_{0 t}\right)^{-\gamma}-\sum_{i=0}^{T-1} \frac{\beta^{i} S_{I i+1 t}}{\left(1-d_{I 0 t}\right)}\left(\frac{c_{i}^{1-\gamma}}{1-\gamma}\right)}{\sum_{i=0}^{T-1} \frac{\beta^{i} S_{I i+1 t}}{\left(1-d_{I 0 t}\right)}}
$$

According to Miller (2000), the VSL amounts to between 127 and 184 times the real GDP per capita, that is, between 2466928 and 3574132 euros (2000). Substituting for those estimates in the above expression, as well as for $\beta=0.96$ and $\gamma=0.83$, one obtains $\alpha=7.007$ under the lower bound for VSL and $\alpha=24.013$ for the upper bound. ${ }^{21}$

Those values for $\alpha$ presuppose the absence of coexistence concerns, i.e. $\delta_{K}=$ 0 for all $K$. Once individuals are interested in other individuals' survival (as in cases $M 3, M 6$ and $M 9$ ), one needs to calibrate $\alpha$ and $\delta_{K}$ jointly. Such a calibration requires to know how individuals value the survival of others.

While studies measuring the value of variations in individual survival prospects are numerous, the same is not true for studies measuring the value of variation in joint survival prospects. One exception is the study by Needleman (1976), which uses data on kidney transplant in order to identify "coefficients of concerns", which are marginal rates of substitution between the risk of death for a given person and the risk of death for another person. ${ }^{22}$ Kidney transplant situations are most relevant for the valuation of coexistence gains, since these are cases where individuals must make a trade-off between the survival of another person (the potential receiver) and their own survival. Hence Needleman's estimated coefficient of concerns based on kidney donations are most relevant for calibrating a lifecycle model with coexistence concerns.

Needleman's estimated coefficients of concern vary depending on the link between the potential donor and the potential receiver. Needleman found that the coefficient of concern for a person and his spouse is equal to about 0.1. This means that, in order to increase the survival chances of his spouse, a person is willing to sacrifice, in terms of his own survival chances, at most one tenth of that variation. When considering other links, coefficients of concerns are even

\footnotetext{
${ }^{20}$ See the Appendix for data on consumption profiles.

${ }^{21}$ Given that Miller's study covers the period 1974-1999, we use, for the calibration, the average levels of the variables (consumptions, survival probabilities) over that period.

${ }^{22}$ Other studies on the interest of individuals for others' survival include Jones-Lee (1991), Araya and Leon (2002) and Strand (2005).
} 
lower: the coefficient of concern of children for their parents equals 0.03 , that is, one third of the coefficient of concern of parents for their children.

Needleman's findings can be used to calibrate parameters $\alpha$ and $\delta_{K}$. In our model, the marginal rate of substitution between the risk of death for the representative person $I$ and the risk of death for another person $K$ is equal to: ${ }^{23}$

$$
\left.\frac{\partial d_{I 0 t}}{\partial d_{K 0 t}}\right|_{U(\cdot)=\bar{U}}=\frac{\frac{\partial U(\cdot)}{\partial d_{K 0 t}}}{\frac{\partial U(\cdot)}{\partial d_{I 0 t}}}=\frac{\delta_{K} \sum_{i=0}^{T-1} \frac{\beta^{i} S_{I K i+1 t}}{\left(1-d_{K 0 t}\right)}}{\left[\begin{array}{l}
\sum_{i=0}^{T-1} \frac{\beta^{i} S_{I i+1 t}\left(\frac{c_{i}^{1}-\gamma}{1-\gamma}+\alpha\right)}{\left(1-d_{I 0 t}\right)} \\
+\sum_{K=1}^{M} \delta_{K} \sum_{i=0}^{T-1} \frac{\beta^{i} S_{I K i+1 t}}{\left(1-d_{I 0 t}\right)}
\end{array}\right]}
$$

One can rewrite that expression as:

$$
\left.\frac{\partial d_{I 0 t}}{\partial d_{K 0 t}}\right|_{U(\cdot)=\bar{U}}=\frac{\frac{\partial U(\cdot)}{\partial d_{K 0 t}}}{\frac{\partial U(\cdot)}{\partial d_{I 0 t}}}=\frac{\delta_{K} \sum_{i=0}^{T-1} \frac{\beta^{i} S_{I K i+1 t}}{\left(1-d_{K 0 t}\right)}}{V S L \times\left(1-d_{I 0 t}\right)\left(c_{0 t}\right)^{-\gamma}}
$$

Hence, for a given value of the VSL, it is possible to calibrate the parameter $\delta_{K}$, since the LHS of that expression is known: it is equal to 0.1 in the case of the survival of a spouse or a child, and equal to 0.03 in the case of the survival of a parent or another person of interest (see Needleman 1976). Thus, the value of the parameter $\delta_{K}$ depends on the kind of welfare interdependency. This depends also on the levels of probabilities of joint survival. Those probabilities obviously depend on the age of the persons under study.

Substituting for the coefficient of concern, for the VSL and for the consumption levels and probabilities of joint survival, one can rewrite $\delta_{K}$ as:

$$
\delta_{K}=\frac{\frac{\frac{\partial U(\cdot)}{\partial d_{K 0 t}}}{\frac{\partial U(\cdot)}{\partial d_{I 0 t}}} \times\left(1-d_{I 0 t}\right)\left(c_{0 t}\right)^{-\gamma} \times V S L}{\sum_{i=0}^{T-1} \frac{\beta^{i} S_{I K i+1 t}}{\left(1-d_{K 0 t}\right)}}
$$

If one takes, for instance, the case of joint survival with children (for which the coefficient of concern equals 0.1 ), one obtains that $\delta_{K}=3.869$ (under the lower bound for VSL) and $\delta_{K}=5.606$ (under the upper bound for VSL). In the case of joint survival with a spouse (belonging to the same generation), one obtains $\delta_{K}=4.301$ (under the lower bound for VSL) and $\delta_{K}=5.841$ (under the upper bound for VSL). Finally, in the case of joint survival with a parent (i.e. previous generation), one obtains $\delta_{K}=1.515$ (under the lower bound for VSL) and $\delta_{K}=2.195$ (under the upper bound for VSL).

Given the additive structure of the individual utility function, the above expression for $\delta_{K}$ is independent from the perspectives of joint survival with other individuals. Therefore, the values obtained for parameters $\delta_{K}$ are independent from the number of persons whose survival matters for the representative individual. Actually, the unique difference induced by the number of persons of

\footnotetext{
${ }^{23} \mathrm{We}$ assume, here again, the independence of individual mortality risks.
} 
interest $M$ lies in the calibration of the parameter $\alpha$. To see this, let us isolate $\alpha$ from the definition of the VSL in our economy. We obtain:

$$
\alpha=\frac{\left[\begin{array}{l}
V S L \times\left(1-d_{I 0 t}\right)\left(c_{0 t}\right)^{-\gamma}-\sum_{i=0}^{T-1} \frac{\beta^{i} S_{I i+1 t}}{\left(1-d_{I 0 t}\right)}\left(\frac{c_{i}^{1-\gamma}}{1-\gamma}\right) \\
-\sum_{K=1}^{M} \delta_{K} \sum_{i=0}^{T-1} \frac{\beta^{i} S_{I K i+1 t}}{\left(1-d_{I 0 t}\right)}
\end{array}\right]}{\sum_{i=0}^{T-1} \frac{\beta^{i} S_{I i+1 t}}{\left(1-d_{I 0 t}\right)}}
$$

That expression gives a unique value for $\alpha$ conditionally on parameters $\beta, \gamma$ and $\delta_{K}$, the latter ones being calibrated on the basis of (21). The level of $\alpha$ derived from that formula depends on the number $M$ of individuals of interests.

Table 1 summarizes the calibration of the preference parameters $\alpha, \beta, \gamma$ and $\delta_{K}$ for societies $M 0, M 3, M 6$ and $M 9$, under the lower and the upper bounds for the value of a statistical life. Those values will be used, in the rest of this section, to compute the consumption equivalent taking variations in survival conditions into account. ${ }^{24}$

\begin{tabular}{c|cc|cc|cc|cc}
\hline \hline Parameters & \multicolumn{2}{|c|}{ Society $M 0$} & \multicolumn{2}{c|}{ Society $M 3$} & \multicolumn{2}{c|}{ Society $M 6$} & \multicolumn{2}{c}{ Society $M 9$} \\
\hline VSL & low & high & low & high & low & high & low & high \\
$\alpha$ & 7.007 & 24.013 & -1.708 & 11.387 & -7.771 & 2.603 & -11.181 & -2.338 \\
$\beta$ & 0.960 & 0.960 & 0.960 & 0.960 & 0.960 & 0.960 & 0.960 & 0.960 \\
$\gamma$ & 0.830 & 0.830 & 0.830 & 0.830 & 0.830 & 0.830 & 0.830 & 0.830 \\
$\delta_{\text {child }}$ & - & - & 3.869 & 5.606 & 3.869 & 5.606 & 3.869 & 5.606 \\
$\delta_{\text {spouse }}$ & - & - & 4.031 & 5.841 & 4.031 & 5.841 & 4.031 & 5.841 \\
$\delta_{\text {parent }}$ & - & - & 1.515 & 2.195 & 1.515 & 2.195 & 1.515 & 2.195 \\
$\delta_{\text {other - gen }+1}$ & - & - & - & - & - & - & 1.161 & 1.682 \\
$\delta_{\text {other - gen 0 }}$ & - & - & - & - & 1.209 & 1.752 & 1.209 & 1.752 \\
$\delta_{\text {other - gen -1 }}$ & - & - & - & - & - & - & 1.515 & 2.195 \\
\hline \hline
\end{tabular}

Table 1: Calibration of preference parameters.

The value assigned to the parameter $\alpha$ decreases, for a given VSL, when one shifts from a society without coexistence concerns (society $M 0$ ) to a society with coexistence concerns (society $M 3$ to $M 9$ ). The intuition goes as follows. When an individual cares only about his own survival, the parameter $\alpha$ alone captures the importance of survival for that individual (independently from the level of consumption). However, once joint survival with other individuals matters, the importance of survival for a person is spread on parameters $\alpha$ and $\delta_{K}$, since individual survival matters also for the joint survival with other persons. Hence, for a given value of the MRS between money and survival for the individual,

\footnotetext{
${ }^{24}$ Note that, as stressed by Costa and Kahn (2004), the VSL has grown during the 20th century. In the light of this, one may compute an equivalent consumption on the basis of several - instead of one - sets of preference parameters. Such a measure of standards of living would incorporate both the improvement in survival conditions and the change in preferences. In this paper, we rely on a fixed set of preference parameters, to capture only the gain in survival conditions.
} 
the introduction of coexistence concerns under the form of parameters $\delta_{K}>0$ implies that the level of $\alpha$ must decrease. This explains why, for a given VSL, the level of $\alpha$ decreases when coexistence concerns become stronger.

\subsubsection{Results}

Before considering the inclusion of gains in coexistence time within an equivalent consumption measure, let us first focus on the special case of a society where individuals care only about their own survival, and not about the survival of others. That case is actually the one that received the largest attention in the literature, following Usher's $(1973,1980)$ pioneer contributions.

Figure 10 compares, in the case of a representative agent of age 25 with no concern for coexistence (society $M 0$ ), unadjusted consumption with adjusted consumption incorporating the gains in survival conditions with respect to the base year $(1820){ }^{25}$

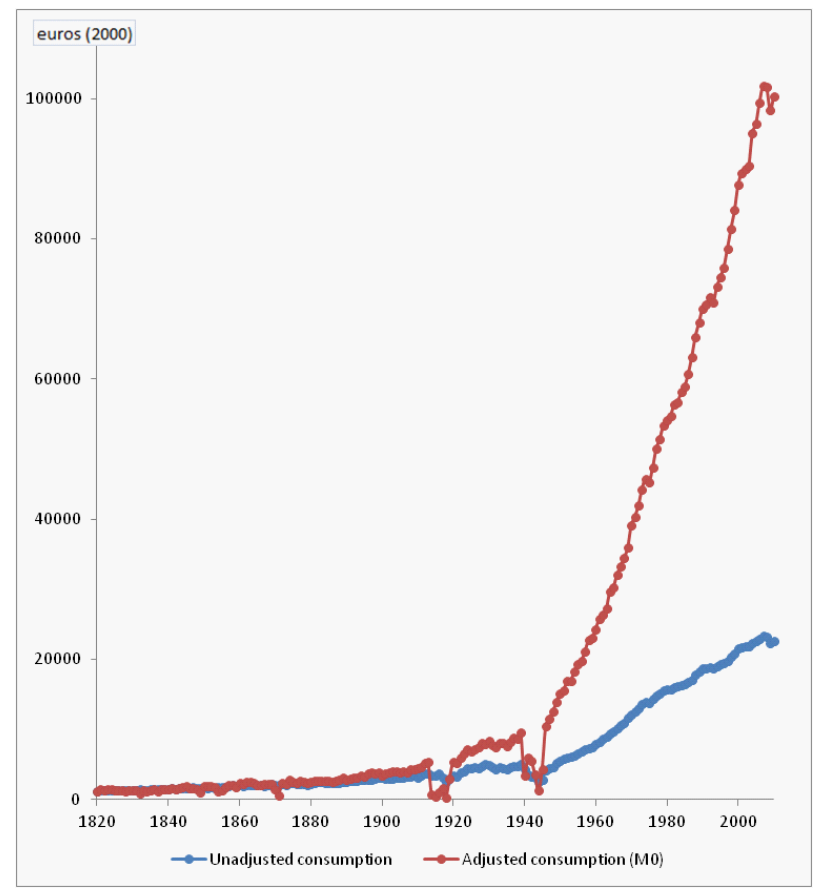

Figure 10: Unadjusted and adjusted consumption for France, 1820-2010 (Society M0, VSL lower bound).

\footnotetext{
${ }^{25}$ Unadjusted consumption is here defined as the constant equivalent consumption level on the life cycle, that is, the hypothetical constant consumption level such that, if enjoyed at all periods of life, this would make the representative agent indifferent with his actual lifetime consumption profile.
} 
During the longest part of the 19th century, adjusted and unadjusted consumption curves are quite close. However, at the end of the 19th century, the two curves start diverging. That divergence becomes much stronger after World War Two. That sizeable gap reflects the high value assigned to gains in life expectancy over the last two centuries. To interpret the large size of the adjustment, let us take the example of year 2000. In 2000, the unadjusted consumption is equal to 21,523 euros, while the adjusted consumption equals 87,694 euros. This means that an annual compensation of 87,694 - 21,523 euros $=66,171$ euros would be needed to allow an individual facing the survival conditions of 1820 to benefit from the same welfare level as the one enjoyed under the survival conditions of 2000. That gap, equal to 66,171 euros annually, is the monetary equivalent of life expectancy gains over 1820-2000.

Let us now consider the value of gains in coexistence time. In order to incorporate the value of coexistence time, we compute equivalent consumptions taking into account not only variations in individual survival prospects, but, also, in joint survival prospects.

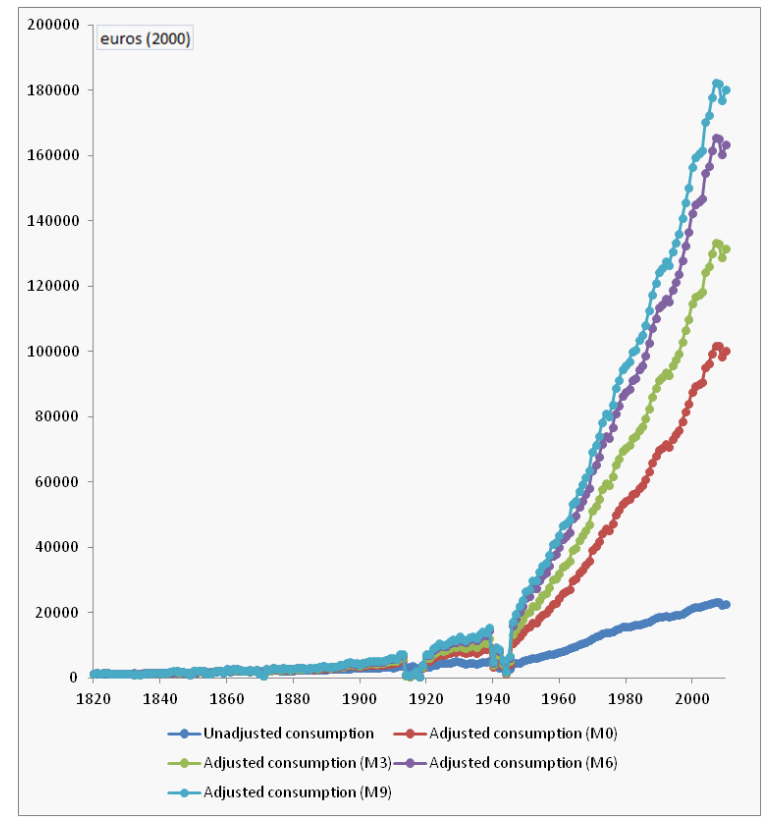

Figure 11: Unadjusted and adjusted consumption for France (1820-2010), societies M0, M3, M6 and M9 (VSL lower bound).

Figure 11 compares the equivalent consumption in the case of, respectively, weak, strong and extended coexistence concerns (i.e. societies $M 3, M 6$ and M9) with the equivalent consumption without coexistence concerns (i.e. society 
M0) and the unadjusted consumption. ${ }^{26}$ Note that all equivalent consumptions curves on Figure 11 rely on exactly the same empirical estimates of the value of a statistical life. The unique difference concerns how parameters $\alpha$ and $\delta_{K}$ are calibrated on the basis of money-risk trade-offs, depending on the strength of coexistence concerns.

Undoubtedly, the incorporation of gains in joint life expectancies raises the equivalent consumption levels. One can, for instance, interpret the gap between the adjusted consumption curves under cases $M 3$ and $M 0$ as reflecting the value, measured in monetary terms, of the improvement of joint survival conditions over the period considered. That value is substantial. For instance, for year 2010, the gap between those two curves is equal to about 31,000 euros. That amount reflects both the strong rise in joint life expectancies over the period 1820-2010, as well as the large weight assigned by individuals to coexistence. Gaps are even larger when considering strong or extended interdependencies (cases $M 6$ and $M 9$ ).

The inclusion of coexistence concerns into the lifecycle model tends to modify significantly the contribution of longevity gains to the measurement of standards of living. The reason why taking coexistence concerns into account affects the picture lies in the fact that joint life expectancies have, over the period considered, grown more strongly than single life expectancies, which leads to larger adjustments.

Finally, let us now calculate consumption equivalents under the upper bound of the VSL. As shown on Figure 12, equivalent consumption curves are now much higher than under the lower bound VSL, whatever coexistence concerns are taken into account or not. This does not constitute a surprise: since Usher's (1973) pioneer works, it is well known that changes in the VSL also affect the level and pattern of equivalent consumption measures incorporating variations in survival conditions. But it should be stressed that, here again, taking coexistence concerns into account affects significantly the contribution of improved survival conditions to living standards.

In sum, the comparison of equivalent consumptions with and without coexistence concerns shows that incorporating coexistence concerns affects the measurement of economic performance significantly. True, even if we focus on the case where there is no coexistence concern, the comparison of the equivalent consumption curve with the unadjusted consumption curve reveals that the improvement of survival conditions contributed a lot to the improvement of standards of living over the last two centuries. However, as shown on Figures 11 and 12, the contribution of improved survival conditions to standards of living is even larger once coexistence concerns are also taken into account. This suggests that shifting from a lifecycle model without interest for others' survival to a more general model with coexistence concerns definitely affects the measurement of the evolution of living standards over the last two centuries.

\footnotetext{
${ }^{26}$ The joint life expectancies taken into account when considering the $M 3, M 6$ and $M 9$ cases are those between persons of age 25 and 0 , ages 25 and 25, as well as between persons of ages 25 and 50 years.
} 


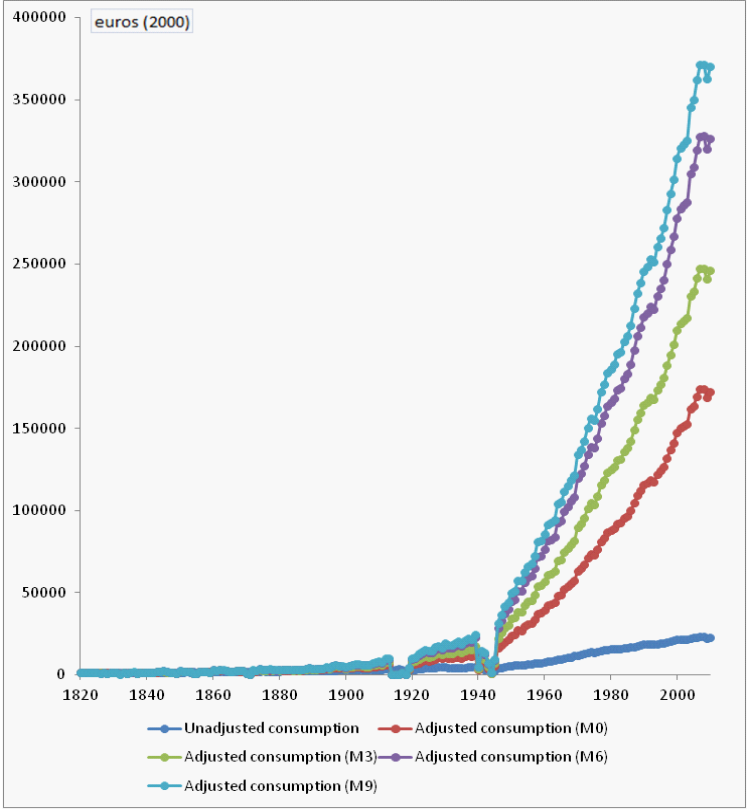

Figure 12: Unadjusted and adjusted consumption for France (1820-2010), societies M0, M3, M6 and M9 (VSL upper bound).

\section{$5 \quad$ Dependent mortality risks}

Up to now, our analyses were based on the postulate of independent individual mortality risks. Although most convenient for analytical purposes, this assumption simplifies the picture, in particular when considering survival within pairs of related individuals. As emphasized by Clayton (1978), related individuals are subject to some common influences, which can make individual mortality risks dependent. The sources of dependent mortality risks within pairs of related individuals are numerous. Members of the same family, such as fathers and sons, share some common influences (i.e. genes and lifestyles), which are likely to lead to some dependence of individual mortality risks.

When considering mortality within couples, a well-known source of dependence consists of the broken heart syndrome. The broken heart syndrome was first illustrated by Parkes et al (1969), who showed, on the basis of a data set including 4,486 55-year-old widowers, that, during the first few months following the death of their wives, widowers face a $40 \%$ increase in mortality risk. This phenomenon, which is an occurrence of positive dependence (in the sense that the survival of the two members of the couple are positively correlated) was also studied by Jagger and Sutton (1991) and by Spreeuw and Owadally (2013). 
Assuming risk independence simplifies the picture too much when considering related individuals. This section explores the impact of relaxing the independence assumption on the measure and valuation of coexistence gains.

\subsection{The survival copula approach}

In the actuarial and epidemiological literatures, a major theoretical tool used for the representation of dependent mortality risks is the copula. ${ }^{27}$ Consider two random variables $X$ and $Y$. Let us denote the distribution function of the random variable $X$ by $F(x) \equiv \operatorname{Pr}(X \leq x)$, and the distribution function of the random variable $Y$ by $G(y) \equiv \operatorname{Pr}(Y \leq y)$. Let us denote the joint distribution of those variables by $H(x, y) \equiv \operatorname{Pr}(X \leq x, Y \leq y)$. Sklar's Theorem (Sklar 1959) states that there must exist a copula $C$ such that:

$$
H(x, y)=C(F(x), G(y))
$$

and that, if $F(x)$ and $G(y)$ are continuous, the copula $C$ is unique. The copula (in dimension 2) is a function $C:[0,1]^{2} \rightarrow[0,1]$ that satisfies the following three conditions (see Charpentier 2014, p. 153):

- Grounded function: $C\left(u_{1}, 0\right)=C\left(0, u_{2}\right)=0$ for all $u_{1}, u_{2} \in[0,1]$,

- Uniform margins: $C\left(u_{1}, 1\right)=u_{1}$ and $C\left(1, u_{2}\right)=u_{2}$ for all $u_{1}, u_{2} \in[0,1]$,

- $C$ is a 2-increasing function, that is, for all $0 \leq u_{i} \leq v_{i} \leq 1$,

$$
C\left(v_{1}, v_{2}\right)-C\left(v_{1}, u_{2}\right)-C\left(u_{1}, v_{2}\right)+C\left(u_{1}, u_{2}\right) \geq 0
$$

When considering the joint survival of individuals, the random variables of interest correspond to the lifetimes of individuals. The relevant representation is based on survival functions. Taking $X$ as the remaining lifetime of some individual $i$ and $Y$ as the remaining lifetime of some individual $j$, the associated survival functions are $\bar{F}(x) \equiv \operatorname{Pr}(X>x)=1-F(x)$ and $\bar{G}(y) \equiv \operatorname{Pr}(Y>y)=$ $1-G(y)$, and the joint survival function is $\bar{H}(x, y) \equiv \operatorname{Pr}(X>x, Y>y)$.

As shown by Nelsen (2007), there exists a relationship between univariate and joint survival functions analogous to the one between univariate and joint distribution functions stated in Sklar's Theorem. Actually, any joint survival function $\bar{H}(x, y)$ with univariate survival functions $\bar{F}(x)$ and $\bar{G}(y)$ admits a copula representation by means of a survival copula $\breve{C}$ :

$$
\bar{H}(x, y)=\breve{C}(\bar{F}(x), \bar{G}(y))
$$

To see this, let us follow Nelsen (2007 p. 32) and rewrite the joint survival function as:

$$
\begin{aligned}
\bar{H}(x, y) & =\operatorname{Pr}(X>x, Y>y) \\
& =1-\operatorname{Pr}(X \leq x)-\operatorname{Pr}(Y \leq y)+\operatorname{Pr}(X \leq x, Y \leq y) \\
& =\bar{F}(x)+\bar{G}(y)-1+C(1-\bar{F}(x), 1-\bar{G}(y))
\end{aligned}
$$

\footnotetext{
${ }^{27}$ On the properties and applications of copulas, see Frees and Valdez (1998), Nelsen (2007), and Charpentier (2014).
} 
Hence, if one defines $\breve{C}\left(u_{1}, u_{2}\right) \equiv u_{1}+u_{2}-1+C\left(1-u_{1}, 1-u_{2}\right)$, we have: $\bar{H}(x, y)=\breve{C}(\bar{F}(x), \bar{G}(y))$. It is straightforward to show that $\breve{C}\left(u_{1}, u_{2}\right)$ is a copula, since it is a grounded function with uniform margins, which is also 2increasing. ${ }^{28}$ It is thus possible to represent a joint survival function in terms of the univariate survival functions by means of a survival copula $\breve{C}$. That representation is analytically convenient, since this makes joint survival conditions depend on two separate things: first, the survival conditions faced by each person individually; second, the structure of dependence between their mortality risks, which is captured by the survival copula.

There exist various kinds of copulas, whose formal properties are studied in Nelsen (2007) and Charpentier (2014). The analysis carried out in the previous sections, which presupposed independent individual mortality risks, relied on a particular copula, called the independent copula, which is denoted by $C^{\perp}$ :

$$
C^{\perp}\left(u_{1}, u_{2}\right)=u_{1} \times u_{2}
$$

and its associated survival copula is:

$$
\breve{C}^{\perp}\left(u_{1}, u_{2}\right)=u_{1}+u_{2}-1+C^{\perp}\left(1-u_{1}, 1-u_{2}\right)=u_{1} \times u_{2}=C^{\perp}\left(u_{1}, u_{2}\right)
$$

Hence, under the independent copula, the bivariate survival probability $S_{i j}\left(x_{i}, x_{j}\right)$ is equal to the product $S_{i}\left(x_{i}\right) \times S_{j}\left(x_{j}\right)$.

In order to account for the dependence of individual mortality risks, we will, in the rest of this section, rely on another copula, proposed by Frank (1979). Frank's copula is defined as follows:

$$
C^{\digamma}\left(u_{1}, u_{2}\right)=\frac{1}{\theta} \ln \left[1+\frac{\left(e^{\theta u_{1}}-1\right)\left(e^{\theta u_{2}}-1\right)}{e^{\theta}-1}\right]
$$

It is easy to show that the survival copula associated to $C^{\digamma}\left(u_{1}, u_{2}\right)$ is equal to $C^{\digamma}\left(u_{1}, u_{2}\right)$. The parameter $\theta$ captures the degree of dependence between individual mortality risks. The special case of independent mortality risks arises when $\theta$ tends towards 0 . When $\theta$ differs from 0 , the mortality risks faced by the individuals under study are dependent. Positive dependence occurs when $\theta<0$, and means that the probability of premature death for one member of the couple is increased by the occurrence of premature death for the other member of the couple. $^{29}$ On the contrary, the case where $\theta>0$ corresponds to a situation of negative dependence: the probability of premature death for one member of the couple is reduced when the other member of the couple dies prematurely.

The reason why we rely here on Frank's copula is that this copula has been widely used in the literature in order to estimate the strength of the dependence of mortality risks within couples. The next subsection uses those estimates to recalibrate our model, in the case of joint survival within couples.

\footnotetext{
${ }^{28}$ For a detailed proof of this, see George et al (2001).

${ }^{29}$ When $\theta$ tends to $-\infty$, Frank's copula reflects the maximal positive dependence between the survival of the two individuals.
} 


\subsection{Joint life expectancies under dependent risks}

In order to examine the robustness of our results to the introduction of dependent mortality risks, we need first to construct measures of coexistence time under dependent mortality risks. This task is complex, since the structure of dependence between mortality risks among related individuals is likely to vary with the particular relation between those individuals.

This section focuses on the case of coexistence between two spouses. The reason is merely that researchers paid lot of attention to the measurement of the broken heart syndrome. Empirical studies aimed at estimating the structure of dependence between individual mortality risks within a couple follow the same general procedure. On the basis of a panel of males and females living in a couple, those studies estimate survival laws for males and females separately, as well as the bivariate survival law. Then, a particular structure of dependence (i.e. a copula) is assumed, and its parameters are estimated on the basis of univariate and bivariate survival laws. Examples of those studies include Frees et al (1996), who estimate the parameter $\theta$ in Frank's copula using longitudinal data from a large Canadian insurer, including about 15,000 couples. The same data were used by Youn and Shemyakin (2001) and by Luciano et al (2007, 2012). Denuit et al (2001) estimated the dependence of mortality risks within couples under other copulas, while relying on data from Brussels cemeteries.

Unlike those articles, our study relies on aggregate life tables from the Human Mortality Database. We only have univariate survival statistics, but we have no statistics for joint survival. Moreover, we do not have, within that database, survival data by marital status, but only for "representative" individuals. For our purpose, we would ideally need data on survival by marital status and on joint survival over the period 1820-2010, but those data are not available.

Despite the limitations of our data, we can introduce dependent mortality risks by means of the following procedure. In order to account for the dependence of mortality risks, our method consists first of reconstructing, on the basis of survival conditions for each member of a hypothetical couple, and under a particular dependence structure, joint survival data. To do this, we use the study of Frees et al (1996), which provided an estimate for the parameter $\theta$ in Frank's copula $(\hat{\theta}=-3.367)$. This negative value indicates that, within a couple, men and women exhibit a significant positive risk dependence, meaning that the happening of premature death for one member of the couple increases the probability of occurrence of premature death for the other member.

Assuming that the structure of dependence of mortality risks within couples has remained stable over the period under study, we can use our lifetables for males and females over that period, as well as the formula for Frank's copula with $\theta=-3.367$, in order to compute probabilities of joint survival to different ages, for a man and a woman of some initial age. ${ }^{30}$ Then, those probabilities are used to compute the associated joint life expectancy.

\footnotetext{
${ }^{30}$ Assuming a constant structure of dependence simplifies the picture. As shown by Luciano et al (2010), the degree of dependence of mortality risks within couples tends to diminish across generations. Relying on a constant dependence structure is thus a simplification.
} 
Figure 13 shows, for the period 1820-2010, the evolution of the joint life expectancy for a man and a woman of age 25 in France, under independent mortality risks (i.e. $\theta$ is close to 0 ) and under the dependence of mortality risks estimated by Frees et al (1996) (i.e. $\theta$ is equal to -3.367). The level of the joint life expectancy under positively dependent mortality risks is, for each year, higher than the joint life expectancy under independent mortality risks. Hence, assuming independent mortality risks made us underestimate the average duration of coexistence. Note, however, that the gap between the two joint life expectancies is - except in war times - inferior to $10 \%$. Moreover, the size of the gap decreased during the 20th century, to represent about $3 \%$ in 2010.

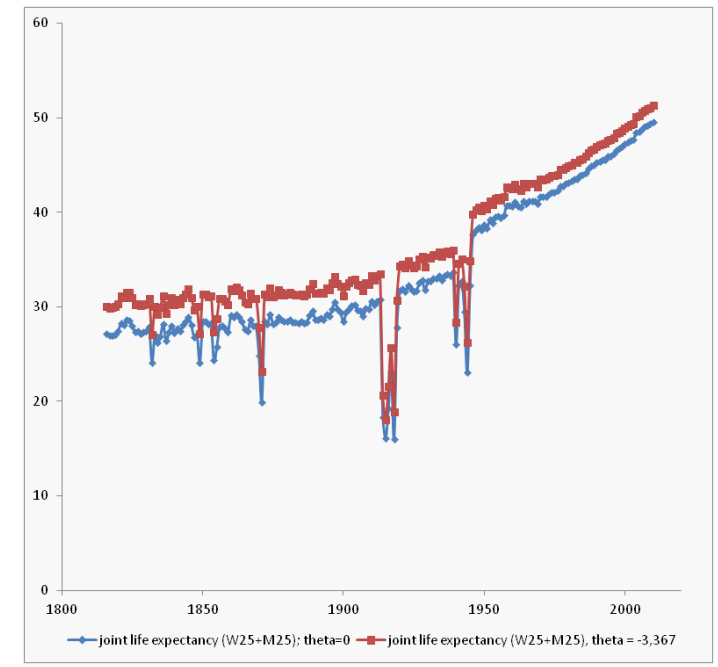

Figure 13: Joint life expectancy for a man and a woman aged 25 , under $\theta \rightarrow 0$ and

$$
\theta=-3.367 \text {. }
$$

Whereas the gap between the two joint life expectancy curves (under dependent and independent mortality risks) is non negligible, the difference between the two curves concerns mainly the levels, but not the slope, of the curves. Given that the slopes of the joint life expectancy curves are quite close, one can expect that the differences in the associated equivalent consumption profiles are also likely to be minor, since these depend on the variation of joint life expectancy with respect to the reference level, and not on their absolute levels. The rest of this section will confirm that intuition.

\subsection{Equivalent consumptions under dependent risks}

We consider here a representative couple, composed of a man and a woman of age 25. Coexistence concerns are thus here oriented, for the representative 
male, towards a unique person (i.e. the representative female), so that we consider here a case that could be called $M 1$. For that particular case, we will compare equivalent consumptions under two distinct specifications: independent mortality risks and dependent mortality risks (using Frank's copula).

In order to calibrate the preference parameters, remind first that the expected lifetime well-being for an agent $I$ who cares about joint survival with an agent $K$ can, under Frank's copula, be rewritten as:

$$
\sum_{s=0}^{T-1} \beta^{s} S_{I s+1}\left(\frac{c_{i}^{1-\gamma}}{1-\gamma}+\alpha\right)+\delta_{\text {spouse }} \sum_{s=0}^{T-1} \beta^{s}\left(\begin{array}{l}
S_{I s+1}+S_{K s+1}-1 \\
+\frac{1}{\theta} \ln \left[1+\frac{\left(e^{\theta\left(1-S_{I s+1}\right)}-1\right)\left(e^{\theta\left(1-S_{K s+1}\right)}-1\right)}{e^{\theta}-1}\right]
\end{array}\right)
$$

Hence the coefficient of concern can now be written as:

$$
\frac{\frac{\partial U(\cdot)}{\partial d_{K 0 t}}}{\frac{\partial U(\cdot)}{\partial d_{I 0 t}}}=\frac{\delta_{\text {spouse }} \sum_{i=0}^{T-1} \frac{\beta^{i} S_{K i+1 t}}{\left(1-d_{K 0 t}\right)}\left[\frac{-e^{\theta}+1+\left(e^{\theta\left(1-S_{I i+1 t}\right)}-1\right)}{e^{\theta}-1+\left(e^{\theta\left(1-S_{I i+1 t}\right)}-1\right)\left(e^{\theta\left(1-S_{K i+1 t}\right)}-1\right)}\right]}{-\sum_{i=0}^{T-1} \frac{\beta^{i} S_{I i+1 t}\left(\frac{c_{i}^{1-\gamma}}{1-\gamma}+\alpha\right)}{\left(1-d_{I 0 t}\right)}+\delta_{\text {spouse }} \sum_{i=0}^{T-1} \frac{\beta^{i} S_{I i+1 t}}{\left(1-d_{I 0 t}\right)}\left[\frac{-e^{\theta+1+\left(e^{\theta\left(1-S_{K i+1 t}\right)}-1\right)}}{e^{\theta}-1+\left(e^{\theta\left(1-S_{K i+1 t}\right)}-1\right)\left(e^{\theta\left(1-S_{I i+1 t}\right)}-1\right)}\right]}
$$

Given that the VSL is here:

$$
\left.\frac{\partial c_{0 t}}{\partial d_{I 0 t}}\right|_{U(\cdot)=\bar{U}}=-\frac{\frac{\partial U(\cdot)}{\partial d_{I 0 t}}}{\frac{\partial U(\cdot)}{\partial c_{0 t}}}=-\frac{\left[\begin{array}{l}
-\sum_{i=0}^{T-1} \frac{\beta^{i} S_{I i+1 t}\left(\frac{c_{i}^{1-\gamma}}{1-\gamma}+\alpha\right)}{\left(1-d_{I 0 t}\right)} \\
+\delta_{\text {spouse }} \sum_{i=0}^{T-1} \frac{\beta^{i} S_{I i+1 t}}{\left(1-d_{I 0 t}\right)}\left[\frac{-e^{\theta}+1+\left(e^{\theta\left(1-S_{K i+1 t}\right)}-1\right)}{e^{\theta}-1+\left(e^{\theta\left(1-S_{K i+1 t}\right)}-1\right)\left(e^{\theta\left(1-S_{I i+1 t}\right)}-1\right)}\right]
\end{array}\right]}{\left(1-d_{I 0 t}\right)\left(c_{0 t}\right)^{-\gamma}}
$$

we can, from the previous expression, rewrite $\delta_{\text {spouse }}$ as:

$$
\delta_{\text {Spouse }}=\frac{\frac{\frac{\partial U(\cdot)}{\partial d_{K 0 t}}}{\frac{\partial U(\cdot)}{\partial d_{I 0 t}}} \times\left(1-d_{I 0 t}\right)\left(c_{0 t}\right)^{-\gamma} \times V S L}{\sum_{i=0}^{T-1} \frac{\beta^{i} S_{K i+1 t}}{\left(1-d_{K 0 t}\right)}\left[\frac{e^{\theta}-1-\left(e^{\theta\left(1-S_{I i+1 t}\right)}-1\right)}{e^{\theta}-1+\left(e^{\theta\left(1-S_{I i+1 t}\right)}-1\right)\left(e^{\theta\left(1-S_{K i+1 t}\right)}-1\right)}\right]}
$$

Using, as above, empirical estimates of the MRS between one's survival and the spouse's survival from Needleman (1976), as well as $\beta=0.96$ and $\gamma=0.83$, we find, under dependent mortality risks, that $\delta_{\text {spouse }}=4.465$ in case of joint survival with the spouse (assuming the lower bound of the VSL). Alternatively, we have, under independent mortality risks, $\delta_{\text {spouse }}=3.947 .^{31}$

\footnotetext{
${ }^{31}$ That value differs from the one appearing in Table 1 (equal to 4.031), for which calculations were based on representative agents without gender differenciation (unlike here, where the two members of the couple are modeled as a woman and a man).
} 
Using that new estimate for $\delta_{K}$, we can now derive the associated value of the parameter $\alpha$ using the above formulation for the VSL:

$$
\alpha=\frac{\left[\begin{array}{l}
V S L \times\left(1-d_{I 0 t}\right)\left(c_{0 t}\right)^{-\gamma}-\sum_{i=0}^{T-1} \frac{\beta^{i} S_{I i+1 t}}{\left(1-d_{I 0 t}\right)}\left(\frac{c_{i}^{1-\gamma}}{1-\gamma}\right) \\
+\delta_{\text {spouse }} \sum_{i=0}^{T-1} \frac{\beta^{i} S_{I i+1 t}}{\left(1-d_{I 0 t}\right)}\left[\frac{-e^{\theta}+1+\left(e^{\theta\left(1-S_{K i+1 t}\right)}-1\right)}{e^{\theta}-1+\left(e^{\theta\left(1-S_{K i+1 t}\right)}-1\right)\left(e^{\theta\left(1-S_{I i+1 t}\right)}-1\right)}\right]
\end{array}\right]}{\sum_{i=0}^{T-1} \frac{\beta^{i} S_{I i+1 t}}{\left(1-d_{I 0 t}\right)}}
$$

We obtain, under dependent mortality risks, that $\alpha=7.129$. In the absence of dependence, we have $\alpha=7.105$.

Having calibrated $\alpha, \beta, \gamma$, and $\delta_{\text {spouse }}$, we compute, for the two cases under study (independent and dependent mortality risks), the equivalent consumption taking into account changes in survival conditions (at the individual and joint levels) since 1820. The associated patterns for adjusted consumptions are quite similar, whatever one relies on independent or on dependent mortality risks. To illustrate this, Figure 14 shows the relative gap between the two equivalent consumption measures. The gap remains lower than $2 \%$, except in war times. ${ }^{32}$

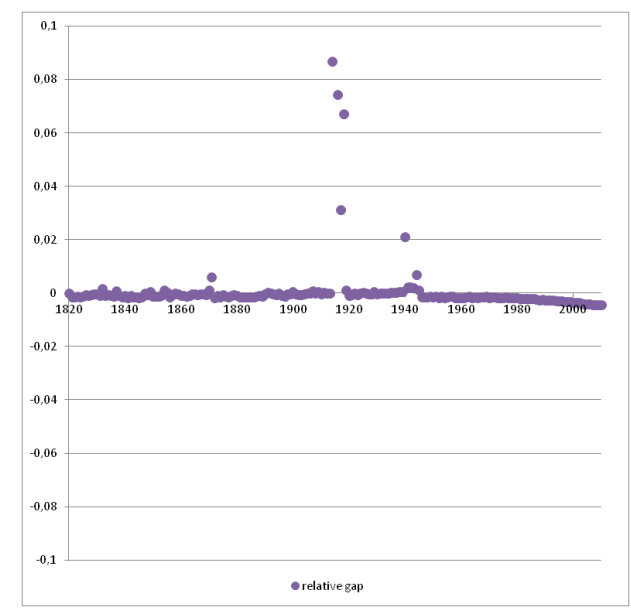

Figure 14: Relative gap between adjusted consumptions under dependent and independent mortality risks.

\footnotetext{
${ }^{32}$ The relative gap is defined as the ratio: [equivalent consumption under dependent risks minus equivalent consumption under independent risks] / equivalent consumption under dependent risks. The higher relative gaps in war times are due to the lowest levels of joint life expectancy for those years.
} 
Our calculations are thus robust to the introduction of dependent individual mortality risks. Robustness holds because introducing risk dependence does not affect the general shape of joint life expectancy, but mainly its level. Hence, since equivalent consumption levels depend on the change in survival conditions with respect to the baseline year (1820), those measures remain almost unchanged when risk dependence is introduced.

Having stressed this, it should be emphasized that our non-exhaustive analysis focused here only on a particular form of mortality risk dependence, between males and females in a couple. Further calculations - as well as more data would be needed to be able to draw a general conclusion on the robustness of equivalent consumption measures to dependent mortality risks.

\section{Concluding remarks}

In the recent years, several studies quantified the contribution of improved survival conditions to living standards by using an equivalent income approach (see Usher 1973, 1980, Williamson 1984, Crafts 1997, Costa and Steckel 1997, Nordhaus 2003, Becker et al 2005, Murphy and Topel 2006; Hall and Jones 2007; Fleurbaey and Gaulier 2009). The goal of this paper was to complement those studies, by focusing on a - so far largely neglected - aspect: coexistence concerns, i.e. interests for the survival of other persons.

For that purpose, we first developed a measure of coexistence time: the joint life expectancy, which is the mathematical expectation of the duration of life for a group of individuals (instead of a single individual). Then, we constructed an equivalent consumption taking into account variations in single and in joint life expectancies. Our application to France (1820-2010) showed that gains in joint life expectancy have been substantial. Moreover, the inclusion of gains in joint life expectancy was shown to affect significantly the measurement of standards of living. Finally, we examined the robustness of our findings to the introduction of dependent mortality risks within couples, and we showed that our consumption equivalent measure is robust to the introduction of risk dependence, since this depends not on the level but on the variation of joint life expectancy over time.

Having summarized our main results, it is worth mentioning some limitations of our approach. First, our analysis supposed that the economy can be represented by means of a representative agent with fixed preferences. That assumption is widespread in the literature on equivalent incomes in a historical perspective (see, among others, Crafts 1997 and Costa and Steckel 1997). However, this assumption constitutes a main limitation of our analysis: a population is composed of individuals with various preferences in terms of consumption profiles and fertility choices. The composition of the population in terms of preferences is also likely to change across generations. Our framework, which involves no heterogeneity and no preference dynamics, cannot take those phenomena into account. Note, however, that the introduction of heterogenous and varying preferences would raise additional difficulties regarding the construction of an equivalent consumption measure. We leave this extension for further research. 
Second, our study focused on the measurement and the valuation of coexistence time from the exclusive perspective of joint survival. As a consequence, we neglected other determinants of coexistence. This constitutes a simplification, since, over the last two centuries, significant changes occurred regarding the age-matching of spouses, the marriage/divorce rates, as well as the number and the spacing of children. ${ }^{33}$ For instance, births postponement implies that the potential duration of coexistence of children with their parents and their grand-parents is reduced. The resulting rise in the parent/children age gap may thus reduce, to some extent, the rise in coexistence time induced by increasing joint life expectancies. ${ }^{34}$ Taking those limitations into account would require to build a lifecycle model with several fertility periods, in such a way as to be able to model changes in the age gap between parents and children. Such models exist in the literature, but the construction of equivalent consumption measures in that extended framework is complex, and would definitely invite another paper. ${ }^{35}$

All in all, although our calculations suggest that the rise in coexistence time has constituted a major source of improvement in living standards, it should be stressed that incorporating coexistence concerns within lifecycle analysis raises difficulties at the level of concepts and data. Hence, it cannot be overemphasized that much work remains to be done, in the future, in order to fully quantify the contribution of coexistence time to the improvement of standards of living.

\section{References}

Andersson, H., Hammitt, J., Lindberg, G., Sundström, K., 2013. Willingness to pay and sensitivity to time framing: a theoretical analysis and an application on car safety. Environmental and Resource Economics, 56 (3), 437-456.

Araya, J., León, C., 2002. Willingness to pay for health risk reduction in the context of altruism. Health Economics, 11(7), 623-635.

Becker, G., Philipson, T., Soares, R., 2005. The quantity and the quality of life and the evolution of world inequality. American Economic Review, 95 (1), 277-291.

Blanchflower, D., Oswald, A., 2004. Well-being over time in Britain and the USA. Journal of Public Economics, 88, 1359-1386.

Blundell, R., Browning, M., Meghir, C., 1994. Consumer demand and the life cycle allocation of household expenditures. Review of Economic Studies, 61 (1), 57-80.

Boissinot, J., 2007. Consumption over the life cycle: facts from France. INSEE, Direction des Etudes et Synthèses Economiques, working paper G2007/09.

Borsch-Suspan, A., 2003. Life-cycle saving and public policy: a cross-national study of six countries, Academic Press, New-York.

Browning, M., Hansen, L., Heckman, J., 1999. Micro data and general equilibrium models. In J. Taylor and M. Woodford (eds.): Handbook of Macroeconomics, vol. 1, Elsevier Sciences.

\footnotetext{
${ }^{33}$ On this, see Gustafsson (2001).

${ }^{34}$ In particular, the reduction in coexistence time induced by birth postponement may be non negligible since the 1970s.

${ }^{35}$ On OLG models with multiple fertility periods, see Pestieau and Ponthiere $(2014,2015)$.
} 
Chakraborty, S., 2004. Endogenous lifetime and economic growth. Journal of Economic Theory, 116, 119-137.

Charpentier, A., 2014. Copules et risques multiples. In: J.J. Droesbeke, M. MaumyBertrand, G. Saporta, C. Thomas-Agnan (eds.) Approches statistiques du risque, Société Française de Statistiques, Editions TECHNIP, Paris.

Clayton, D., 1978. A model for association in bivariate life tables and its application in epidemiological studies of familal tendency in chronic disease incidence. Biometrika, 65 (1), 141-151.

Crafts, N., 1997. The Human development index and changes in standards of living: some historical comparisons. European Review of Economic History, 1, 299-322.

Costa, D., Kahn, M., 2004. Changes in the value of life, 1940-1980. Journal of Risk and Uncertainty, 29, 159-180.

Costa, D., Steckel, R., 1997. Long-term trends in health, welfare and economic growth in the United States. In R. Steckel et R. Floud (eds.), Health and Welfare during Industrialization, NBER Project Report, Chicago IL, University of Chicago Press.

Cropper, M., Hammitt, J., Robinson, L., 2011. Valuing mortality risk reductions: progress and challenges. Annual Review of Resources Economics, 3 (1), 313-336.

de la Croix, D., Michel, P., 2002. A theory of economic growth. Cambridge University Press, Cambridge.

Denuit, M., Dhaene, J., Le Bailly de Tilleghem, C., Teglem, S., 2001. Measuring the impact of dependence among insured life lengths. Belgian Actuarial Bulletin, 1, 18-39.

Fleurbaey, M., Gaulier, G., 2009. International comparisons of living standards by equivalent incomes. Scandinavian Journal of Economics, 111, 597-624.

Frank, M., 1979. On the simultaneous associativity of $\mathrm{F}(\mathrm{x}, \mathrm{y})$ and $\mathrm{x}+\mathrm{y}-\mathrm{F}(\mathrm{x}, \mathrm{y})$. Aequationes Math. 19, 194-226.

Frees, E., Carriere, J., Valdez, E., 1996. Annuity valuation with dependent mortality. Journal of Risk and Insurance, 63 (2), 229-261.

Frees, E., Valdez, E., 1998. Understanding relationships using copulas. North American Actuarial Journal, 2 (1), 1-25.

Georges, P., Lamy, A-G., Nicolas, E., Quibel, G., Roncalli, T., 2001. Multivariate survival modelling: a unified approach with copulas. Groupe de Recherche Opérationnelle Crédit Lyonnais, France.

Gourinchas, P.-O., Parker, J., 2002. Consumption over the life-cycle. Econometrica, 70, $47-89$

Gustafsson, S., 2001. Theoretical and empirical considerations on postponement of maternity in Europe. Journal of Population Economics, 14, 225-247.

Hall, R., Jones, C., 2007. The value of life and the rise in health spending. Quarterly Journal of Economics, 122 (1), 39-712.

Human Mortality Database, 2013. University of California, Berkeley (United States), Max Planck Institute for Demographic Research (Germany). Available at: http://www.mortality.org

Jagger, C., Sutton, C., 1991. Death after marital bereavement - is the risk increased? Statistics in Medicine, 10, 395-404.

Jappelli, T., Modigliani, F., 2005. The age-saving profile and life-cycle hypothesis. In F. Francesco (ed.): The Collected Papers of Franco Modigliani, vol. 6, chapter 5, 141-172, MIT Press, Cambridge MA. 
Johansson, P-O., 2001. Evaluating health risk. An economic approach. Cambridge University Press.

Jones-Lee, M., 1991. Altruism and the value of other people's safety. Journal of Risk and Uncertainty, 4, 213-219.

Le Bras, H., 1973. Parents, grands-parents, bisaïeux. Population, 28, 9-37.

Lee, R., Tuljapurkar, S., 1997. Economic consequences of ageing for populations and individuals death and taxes: longer life, consumption and social security. Demography, 34, 67-81.

Luciano, E., Spreeuw, J., Vigna, E., 2008. Modeling stochastic mortality for dependent lives. Insurance: Mathematics and Economics, 43, 234-244.

Luciano, E., Spreeuw, J., Vigna, E., 2010. Cross generational comparison of stochastic mortality of coupled lives. University of Torino, Working Paper.

Maddison Project, data available at http://www.ggdc.net/maddison/maddison-project/home.htm.

Miller, T., 2000. Variations between countries in values of statistical life. Journal of Transport Economics and Policy, 34 (2), 169-188.

Murphy, K., Topel, R., 2003. Measuring gains from medical research: an economic approach, Chicago, IL, University of Chicago Press.

Needleman, L., 1976. Valuing other people's lives. Manchester School, 44, 309-342.

Nelsen, R., 2007. An introduction to copulas. Springer Series in Statistics.

Nordhaus, W., 2003. The health of nations: the contribution of improved health to living standards. In K. Murphy and R. Topel (eds.): Measuring Gains from Medical Research: An Economic Approach, Chicago, IL, University of Chicago Press.

Nordhaus, W., Tobin, J., 1972. Is Growth Obsolete? in Economic Growth, fiftieth anniversary, Colloqium 5, National Bureau of Economic Research.

North, D., 1994. Economic performance through time. American Economic Review, 84, 359-368.

Parkes, C., Benjamin, B, Fitzgerald, R., 1969. Broken heart: a statistical study of increased mortality among widowers. British Medical Journal, 1, 740-743.

Pestieau, P., Ponthiere, G., 2014. Optimal fertility along the life cycle. Economic Theory, 55 (1), 185-224.

Pestieau, P., Ponthiere, G., 2015. Optimal lifecycle fertility in a Barro-Becker economy. Journal of Population Economics, 28 (1), 45-87.

Poterba, J., 1994. International comparison of household saving, University of Chicago Press, Chicago.

Sandberg, L., Steckel, R., 1997. Was industrialization hazardous to your health? Not in Sweden! In R. Steckel and R. Floud (eds.), Health and Welfare during Industrialization, NBER Project Report, Chicago IL, University of Chicago Press.

Sen, A., 1973. On the development of basic income indicators to supplement GNP measures. United Nations Bulletin for Asia and the Far East, 24, 1-11.

Sen, A., 1998. Mortality as an indicator of economic success and failure. Economic Journal, 108, 1-25.

Sklar, A., 1959. Fonctions de répartition à n dimensions et leurs marges, Publications de l'Institut de Statistique de l'Université de Paris, 8, 229-231.

Spreeuw, J., Owadally, I., 2013. Investigating the broken-heart effect: a model for shortterm dependence between the remaining lifetimes of joint lives. Annals of Actuarial Science, 7 (2), 236-257. 
Strand, J., 2005. Individual and household values of mortality reductions with intrahousehold bargaining. Journal of Risk and Uncertainty, 31 (2), 217-236.

Usher, D., 1973. An imputation to the measure of economic growth for changes in life expectancy. In M. Moss (ed.), The Measurement of Economic and Social Performance, NBER, New-York.

Usher, D., 1980. The measurement of economic growth, Columbia University Press, NewYork.

Viscusi, K., 1998. Rational risk policy. The Arne Ryde Memorial lecture series, Clarendon Press, Oxford.

Viscusi, K., Aldy, J., 2004. The value of a statistical life: a critical review of market estimates throughout the world. Journal of Risk and Uncertainty, 27 (1), 5-76.

Williamson, J., 1984. British mortality and the value of life, 1781-1931. Population Studies, 38, 157-172.

Youn, H., Shemyakin, A., 2001. Pricing practices for joint last survivor insurance. Actuarial Research Clearing House, 1.

\section{Appendix}

Demographic data On the demographic side, we use data from the lifetables of the Human Mortality Database. In order to compute the equivalent income incorporating the value of changes in global survival conditions, we use individual probabilities of survival at all ages of life, for all years under study (from 1820 to 2010). We also use the probabilities of joint survival, for different pairs of individuals (varying with the age and the sex of the members of the pair), also for the period 1820-2010.

Consumption profiles As far as consumption statistics are concerned, we use consumption profiles by age (between age 25 and age 80 ) estimated for France by Boissinot (2007). Those lifetime consumption profiles were estimated on the basis of 5 successive waves of the INSEE Survey on Household Budgets. ${ }^{36}$ Each wave includes about 10000 households, which implies a total sample size of between 25000 and 30000 individuals. On the basis of that pseudo-panel, consumption profiles were estimated on an age interval between 25 years and 80 years. Figure A1 below shows the consumption profile obtained by Boissinot on the basis of 15 cohorts, born between 1960 and 1975. That consumption profile has been normalized, a unitary value being assigned to consumption at the beginning of the lifecycle (i.e. at age 25).

The consumption profile estimated by Boissinot exhibits the standard invertedU shape. ${ }^{37}$ The maximum consumption is achieved around age 45. After age

\footnotetext{
${ }^{36}$ Consumption profiles are estimated by regressing the logarithm of consumption on a constant, on age, (age $)^{2},(\text { age })^{3}$, (age $)^{4}$ and (age $)^{5}$, as well as on dummy variables for the different years of birth. The latter control variables are used to neutralize the impact of cohort effects.

${ }^{37}$ See Poterba (1994), Lee and Tuljapurkar (1997), Gourinchas and Parker (2002), BorschSuspan (2003), Japelli and Modigliani (2005).
} 
50 , consumption starts falling continuously, to reach, at age 80 , a level equal to about $70 \%$ of the consumption at age 25 . The consumption profile on Figure A1 stops at age 80 . This is problematic for the monetization of longevity gains, since a significant part of those gains concern ages higher than 80 . This is the reason why we extended the consumption profile estimated by Boissinot until the age of 110 . For that purpose, we calculated the growth rate of consumption between ages 75 and 80 , and we extrapolated the rest of the consumption profile by applying that growth rate to the age interval 80-110 (see Figure A2).

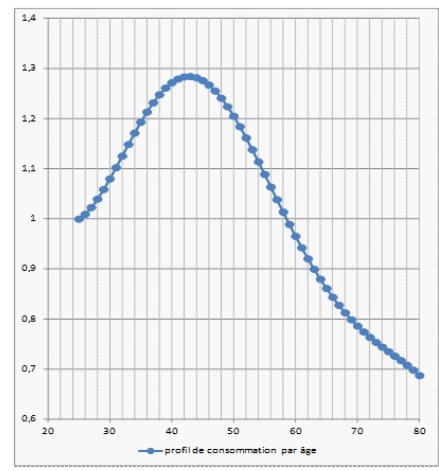

Fig. A1: Normalized consumption profile (age $25-80)$.

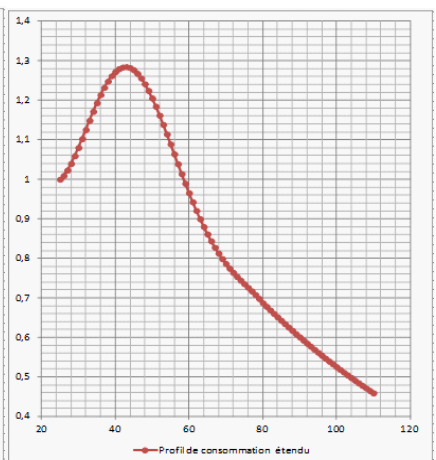

Fig. A2: Extended consumption profile (age 25-110).

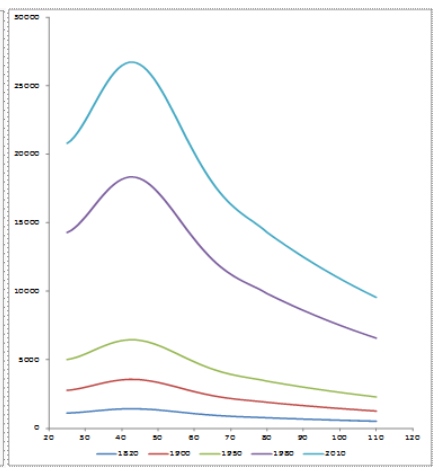

Fig. A3: Lifetime consumption profiles, 1820-2010 (in 2000 euros).

The lifetime consumption profile on Figure A2 was then used to derive, by extrapolation, lifetime consumption profiles for all years considered in this study (1820-2010). For that purpose, we started from the lifetime consumption profile estimated by Boissinot (2007) for year 2000, and we used the levels of income per head for all years between 1820 and 2010 (sources: the Angus Maddison Project), in such a way as to derive the corresponding lifetime consumption profiles associated to those years. For each year, the consumption profile is assumed to keep the same general shape, which is characterized by the proportionality coefficients appearing on Figure A2. Figure A3 shows some extrapolated lifetime consumption profiles, for years between 1820 and 2010 .

This extrapolation amounts to assuming that intertemporal trade-offs did not change significantly over time, and that differentials in income per head explain all differences observed, year after year, in consumption levels at a given age. Obviously, that assumption can only be regarded as a first proxy. On a period as large as two centuries, the strong improvement of survival conditions may have affected savings behaviors, and, thus, the shape of the lifetime consumption profile. ${ }^{38}$ However, this extrapolation is required given the lack of historical data on lifetime consumption profiles over that period.

${ }^{38} \mathrm{On}$ the link between life expectancy and the propensity to save, see Chakraborty (2004). 